\title{
Trends in Dryness Index Based on Potential Evapotranspiration and Precipitation over 1961-2099 in Xinjiang, China
}

\author{
Yi Li and Mudan Zhou \\ College of Water Resources and Architecture Engineering, Northwest Agriculture and Forestry University, Yangling, \\ Shaanxi 712100, China \\ Correspondence should be addressed to Yi Li; liyikitty@126.com
}

Received 22 August 2014; Accepted 2 October 2014; Published 4 November 2014

Academic Editor: Harry D. Kambezidis

Copyright (C) 2014 Y. Li and M. Zhou. This is an open access article distributed under the Creative Commons Attribution License, which permits unrestricted use, distribution, and reproduction in any medium, provided the original work is properly cited.

Under the background of global warming, deep understanding for drought-related index is important. The spatial distributions and trends in annual mean (AM) climatic data, including $P_{\mathrm{AM}}, \mathrm{ET}_{o, \mathrm{AM}}$, and $\mathrm{DI}_{\mathrm{AM}}$ in Xinjiang, China, were analyzed. Statistical downscaling model (SDSM) was applied. Future $P_{\mathrm{AM}}, \mathrm{ET}_{o, \mathrm{AM}}$, and $\mathrm{DI}_{\mathrm{AM}}$ series were generated and used to analyze their temporal trends, along with the historical climatic data. The results showed that (1) over 1960-2010, $\mathrm{DI}_{\mathrm{AM}}$ varied greatly and ranged from 1.5 to 479.6. Trends in $\mathrm{DI}_{\mathrm{AM}}$ decreased significantly. The regional climate turned to be from arid to humid in the past; (2) over 2015-2099, $\mathrm{DI}_{\mathrm{AM}}$ ranged between 1.9 and 198.5 under A2 scenario and 1.6 and 130.4 under B2 scenario. Trends in $\mathrm{DI}_{\mathrm{WR}}$ decreased insignificantly under A2 scenario and significantly under B2 scenario, indicating a weak drought stress from the future climate; (3) the modified Mann-Kendal (MKK) test generally decreased the significance of the trends because it considered the limitation of serial autocorrelation. Robust trend test of MMK method was recommended considering its rigor property. In conclusion, the drought in Xinjiang tends to be relieved over 2015-2099 compared to 1960-2010.

\section{Introduction}

It has been widely recognized that the increment of greenhouse gases in the atmosphere is the primary cause of the observed global warming [1]. Climate change is expected to have a range of crucial consequences including droughts [2], sea level rise, intense rain, and flooding, of which droughts are recognized as an environmental disaster and have raised the interest of scientists across various disciplines. Drought is generally characterized by a considerable decrease in water availability caused by a deficit in precipitation over a large area $[3,4]$. Droughts are often classified into four categories including meteorological, hydrological, agricultural, and social-economic types [5]. Drought indices were presented for assessing the severity of a drought and defining different drought parameters [6]. There are some commonly used drought indices, for example, dryness index (DI) [7, 8], Palmer Drought Severity Index (PDSI) [9], Crop Moisture Index (CMI) [10], Standardized Precipitation Index (SPI) [11], Soil Moisture Drought Index (SMDI) [12], and Vegetation Condition Index (VCI) [13]. Other droughtrelated indices including Standardized Precipitation Evapotranspiration Index (SPEI) [14, 15], monthly precipitation anomalies [16], and El Nino-Southern Oscillation (ENSO) are also used in drought analysis. Among the presented drought indices, DI, which is the ratio of potential evaporation $\left(\mathrm{ET}_{o}\right)$ to precipitation $(P)$, is useful for classifying the type of climate in relation to the water availability and has been utilized in different regions of the world [17-19]. Climatic regimes can be divided into 4 groups including arid $(12>\mathrm{DI} \geq 5)$, semiarid $(5>\mathrm{DI} \geq 2)$, subhumid $(2>\mathrm{DI} \geq 0.75)$, and humid regions $(0.75>$ DI $\geq 0.375)$, respectively [8].

General circulation models (GCMs), which include numerical coupled models and represent various earth systems, are important tools to assessing climate change effects on droughts [20]. However, they are unable to resolve significant subgrid scale feature [21]. Downscaling technique is generally needed to translate large-scale GCMs output onto a finer resolution. Two fundamental approaches exist for downscaling: (1) a dynamical approach where a higher 
resolution climate model is embedded within a GCM and (2) a statistical method where empirical relationships could be established between GCM-resolution and local climate variables [22]. In contrast, statistical downscaling (SDS) is computationally efficient and can be suitably used to perform the spatial downscaling and bias correction for a large amount of GCM outputs and has become a commonly used tool in climate impact studies. Various studies demonstrated that the overall performance of statistical and dynamic downscaling was similar in reproducing the present-day climate for the respective regions [23].

The SDS technique involves developing a quantitative relationship between large-scale climate variables (predictors) and local surface variables (predictands). SDS has many advantages. SDS can provide point-scale climatic variables from GCM-scale output; it can be used to derive variables not available from regional climate models (RCMs); it is easily transferred to other regions based on standard and accepted statistical procedures; and it is able to directly incorporate observations into method [22]. Many techniques have been developed for SDS. Wilby et al. [24] introduced an SDS model (SDSM) to assess regional climate change impacts. Mehrotra and Sharma [25] presented a multisite rainfall downscaling model (MMM-KDE) and Mehrotra et al. [26] applied the model in projection of future rainfall in India combined with 5 GCMs. An analogue downscaling method was applied by Timbal [27] and has been used for simulating the decline in rainfall in various regions within Australia $[28,29]$. Sunyer et al. [30] compared five SDS methods, including two statistical correction methods and three weather generators (WG). Chen et al. [31] assessed the uncertainty of six empirical downscaling methods in quantifying the hydrological impact of climate change over two North American river basins. Chandler and Wheater [32] proposed a Generalised Linear Model (GLM) for daily time series and used it to analyze and simulate spatial daily rainfall given natural climate variability influences in the UK [33]. Hughes et al. [34] described a nonhomogeneous hidden Markov model. Tumbo et al. [35] assessed the validity of downscaling together with evaluation of GCM models (CGCM, CRNM, ISPL, and ECHAM) for projecting climate change in Same (Northeastern Tanzania) using a self-organizing maps technique. The empirical downscaling methods, which were grouped into change factor and bias correction approaches, were also commonly used [36]. Support vector machine (SVM) and multivariate analysis were applicable in SDS [37]. Frost et al. [38] compared six downscaling methods and evaluated those using Australia multisite rainfall data. It was considered that no single model performed well over all timescales/statistics and the user should beware of model limitations when applying downscaling methods for various purposes [38].

Xinjiang Autonomous Region has an area of 1.66 million $\mathrm{km}^{2}$ and takes up roughly one sixth of the total area of China. It is located in the northwest inland of China and is distant from any coast. The climate in Xinjiang is dry with many hours of sunshine and large temperature differences between day and night. The surface water and groundwater resources in Xinjiang rank 14 and 4, respectively, out of 31 provinces in
China with highly uneven spatial distributions. The average annual precipitation in Xinjiang is only $147 \mathrm{~mm}$ while the average annual evaporation is $1512 \mathrm{~mm}$ [39]. Xinjiang is a typical and representative arid region in China and is also typical of other arid regions around globe. Under the global climate warming background [1], the climate in Xinjiang transforms from warm-dry to warm-wet trends [40,41], accompanied with the abrupt change of precipitation and its extreme indices [42]. Although there has been research which focused on the historical variations of various climate elements [43] and specifically in Xinjiang [41], the changing trends of future precipitation in this region are still not clear. Because the variability of weather elements (including precipitation, air temperature, wind speed, relative humidity, etc.) is important for the early warning of water-related hazards, studies on the trends of both historical and future droughts in Xinjiang are necessary in order to keep stable development of the regional economy and the health of people's livelihoods.

The objectives of this study are (1) to project annual mean precipitation $\left(P_{\mathrm{AM}}\right)$, potential evaporatranspiration $\left(\mathrm{ET}_{o, \mathrm{AM}}\right)$ at the multisite of the study region over 2015-2099 under A2 (medium-high carbon emissions) and B2 (medium-low carbon emissions) scenarios of the IPCC SRES (Intergovernmental Panel on Climate Change, Special Report on Emission Scenarios), using an SDS method, NECP (National Center for Environmental Prediction) reanalysis data and the observed weather data and to obtain annual mean dryness index $\left(\mathrm{DI}_{\mathrm{AM}}\right)$ series over 2015-2099; (2) to analyze the trends of $P$, $\mathrm{ET}_{o}$, and DI series over 1961-2099 using a modified MannKendall (MMK) method, in which serial autocorrelations are taken into account. Regional trends of drought are given, which could be a reference for the climatic precaution and disaster control.

\section{Data and Methodology}

2.1. Data Sources. Data used in this study include (1) the observed weather data (wind speed, relative humidity, air temperature, sunshine hour, and precipitation) from 41 sites in Xinjiang Autonomous Region in China over 1961-2010 which were collected from Meteorological Data Sharing Service Network in China (http://cdc.cma.gov.cn/home.do), (2) GCM data over 1961-2099 from Hadley Centre of United Kingdom Meteorological Office, and (3) NCEP reanalysis data, including 26 predictor variables over 1961-2000.

HadCM3 (Hadley Centre Coupled Model, version 3, [44]), which gave moderate results compared to the other models [1], is employed in this study to provide future predictors. A2 and B2 scenarios of the IPCC SRES for the period 1961-2099 are chosen to give different possibilities. B2 describes a world with intermediate population and economic growth, emphasizing local solutions to economic, social, and environmental sustainability, and A2 describes a very heterogeneous world with high population growth, slow economic development, and slow technological change [1]. Data from HadCM3 under A2 and B2 scenarios are used in this study because (1) HadCM3 generates the past climate for 
China better than the other GCMs [45] and (2) it provides daily outputs of the 26 atmospheric predictor variables and can be easily obtained from the SDSM website (http://copublic.lboro.ac.uk/cocwd/SDSM/).

\subsection{Estimation of Standard Potential Evapotranspiration.} Potential evapotranspiration is based on the calculated rate of evapotranspiration from a hypothetical reference crop with a height of $0.12 \mathrm{~m}$, an albedo of 0.23 , and a fixed surface resistance of $70 \mathrm{~s} \mathrm{~m}^{-1}$. FAO-56 Penman-Monteith equation is used for estimating $\mathrm{ET}_{o}[46]$ :

$$
\mathrm{ET}_{o}=\frac{0.408 \Delta\left(R_{n}-G\right)+\gamma(900 /(T+273)) u_{2}\left(e_{s}-e_{a}\right)}{\Delta+\gamma\left(1+0.34 u_{2}\right)}
$$

where $\mathrm{ET}_{o}$ is the potential evapotranspiration $\left(\mathrm{mm} \mathrm{day}^{-1}\right), G$ is soil heat flux $\left(\mathrm{MJ} \mathrm{m}^{-2} \mathrm{day}^{-1}\right), T$ is mean air temperature at $2 \mathrm{~m}\left({ }^{\circ} \mathrm{C}\right), u_{2}$ is wind speed at $2 \mathrm{~m}\left(\mathrm{~m} \mathrm{~s}^{-1}\right), e_{s}$ is saturation vapor pressure $(\mathrm{kPa}), e_{a}$ is actual vapor pressure $(\mathrm{kPa}), e_{s}-$ $e_{a}$ is saturation vapor pressure deficit $(\mathrm{kPa}), \Delta$ is slope of vapor pressure curve $\left(\mathrm{kPa}^{\circ} \mathrm{C}^{-1}\right), \gamma$ is psychrometric constant $\left(\mathrm{kPa}^{\circ} \mathrm{C}^{-1}\right)$, and $R_{n}$ is net radiation $\left(\mathrm{MJ} \mathrm{m}^{-2} \mathrm{day}^{-1}\right)$. The net radiation $\left(R_{n}\right)$ is the difference between the incoming radiation $\left(R_{\mathrm{ns}}, \mathrm{MJ} \mathrm{m}^{-2}\right.$ day $\left.^{-1}\right)$ and the outgoing radiation

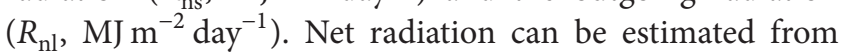
Equations (21) to (25), (34) to (36), and (38) to (40) in Allen et al. [46].

2.3. Projection of Daily ET $T_{o}$ and Precipitation Data. SDSM version 4.2 is used to project future daily $\mathrm{ET}_{o}$ and $P$ before 2100. SDSM is best described as a hybrid of regression based and stochastic weather generator downscaling methods [24]. The empirical relationship between predictand at each station and large-scale regional weather indices (predictors) obtained from the NCEP reanalysis for the climate over 1961-2000 is established first. The nearest NCEP grids to the stations were chosen so that the station data were well related to gridded NCEP data. The period 1961-2000 is split into 1961-1990 and 1991-2000 to develop and validate regression equations. Bias correction was applied to match the observed and downscaled precipitation total. Variance inflation is also used to increase the variance of $P$ to agree better with observations. Coefficients of determination $\left(R^{2}\right)$ and Nash-Sutcliffe model efficiency $\left(E_{\mathrm{ns}}\right)$ are used to assess the performance of SDSM for reproducing $P$ over 1961-2000. Taking precipitation as an example, $E_{\mathrm{ns}}$ is calculated by

$$
E_{\mathrm{ns}}=1-\frac{\sum_{i=1}^{n}\left(P_{\mathrm{oi}}-P_{\mathrm{pi}}\right)^{2}}{\sum_{i=1}^{n}\left(P_{\mathrm{oi}}-P_{\mathrm{ave}}\right)^{2}}
$$

where $P_{\mathrm{oi}}$ is the observed precipitation at the $i$ th day, $P_{\mathrm{pi}}$ is the produced precipitation for the $i$ th day obtained from SDSM software, $P_{\text {ave }}$ is the average value of the observed daily weather data, and $n$ is the number of the observations. When $P_{\mathrm{oi}}$ is equal to $P_{\mathrm{pi}}, E_{\mathrm{ns}}$ is equal to 1 .
The established empirical relationship, taking $P$ as an example, is described as follows:

$$
P=\sum_{i=1}^{26} a_{i} x_{i}
$$

where $x_{i}$ is the $i$ th predictor derived by NCEP. Equation (3) is then applied to downscale ensembles of the same local variables for the future climate provided by HadCM3 under A2 and B2 scenarios over 2015-2099. The historical data from 1961 to 2010 and the consecutive 89-year time slices from 2015 to 2099 are used to examine the temporal trends of $P$.

Daily precipitation variations in the whole region $\left(P_{\mathrm{WR}}\right)$ could be obtained by introducing a parameter-area weight $\left(A_{W}\right) . A_{W}$ is the ratio of the representative area of each station to the area of the whole region. The representative area of each station is obtained using Thiessen polygon method. $P_{\mathrm{WR}}$ is calculated by

$$
P_{\mathrm{WR}}=\sum_{i=1}^{41} A_{W, i} P_{i}
$$

where $P_{i}$ is the daily precipitation over 2015-2099 at the $i$ th weather station. Estimations of $\mathrm{ET}_{o}$ and DI in the whole region are similar to $P$.

2.4. Estimation of Dryness Index. The dryness index (DI) is estimated by

$$
\mathrm{DI}=\frac{\mathrm{ET}_{o}}{P} .
$$

Inverse distance weight (IDW) interpolation method in Arcmap 10.2 is used to interpret the spatial distributions of $P$, $\mathrm{ET}_{o}$, and DI.

2.5. Trend Detection Test. The existence of annual trends in the data series was analyzed based on the Mann-Kendall (MK) statistical test $[47,48]$ for two periods of 1961-2010 and 2015-2099. Taking precipitation $(P)$ as an example, the test statistic, Kendall's $S$, is calculated as [48]

$$
S=\sum_{k=1}^{N-1} \sum_{l=k+1}^{N} \operatorname{sgn}\left(P_{l}-P_{k}\right)
$$

where $P_{k}$ and $P_{l}$ are the values in the $k$ th and $l$ th year, $n$ is the length of the data set, and sgn $(x)$ is the sign function. The variance $\left(\sigma^{2}\right)$ is given by [49]

$$
\sigma^{2}=\frac{n(n-1)(2 n+5)}{18} .
$$

The standardized test statistic $Z$ is computed by [50]

$$
Z= \begin{cases}\frac{S-1}{\sigma} & \text { if } S>0, \\ 0 & \text { if } S=0, \\ \frac{S+1}{\sigma} & \text { if } S<0 .\end{cases}
$$




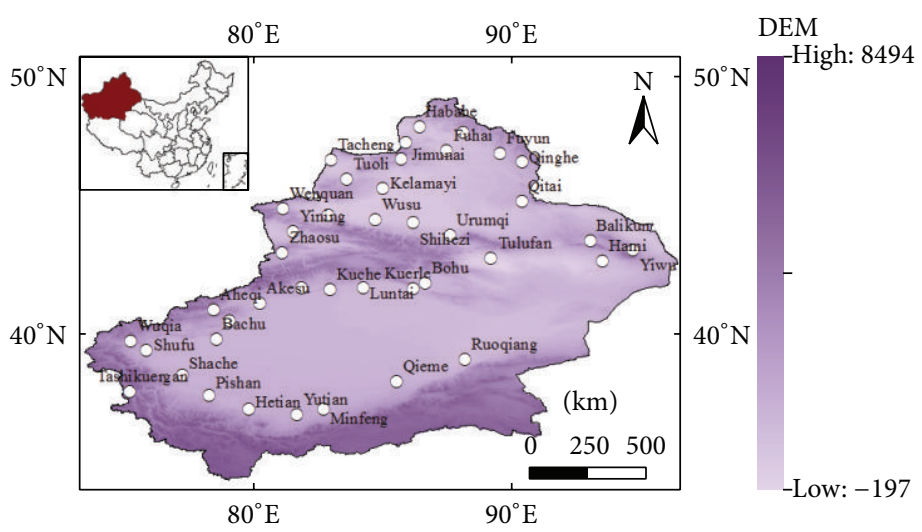

FIGURE 1: Digital elevation model (DEM) showing the geological location of the weather stations used in this study.

$Z$ follows the standard normal distribution with a mean of zero and variance of one under the null hypothesis of no trend in the series. The null hypothesis is rejected if $|Z| \geq Z_{1-\alpha / 2}$ at the confidence level of $\alpha$, where $Z_{1-\alpha / 2}$ is the $(1-\alpha / 2)$ quantile. If $Z$ is positive (negative), the series $P$ has an upward (downward) trend. At $\alpha=0.05$, if $|Z|>1.96$, then the trend is significant. A correction factor $n^{s}$ for limiting the influence of serial autocorrelation on the MK test is introduced $[51,52]$ to estimate the modified standardized MK statistic, $Z^{*}$ :

$$
Z^{*}=\frac{Z}{\sqrt{n^{s}}}
$$

where

$$
n^{s}= \begin{cases}1+\frac{2}{n} \sum_{j=1}^{n-1}(n-1) r_{j} & \text { for } j>1 \\ 1+2 \frac{r_{1}^{n+1}-n r_{1}^{2}+(n-1) r_{1}}{n\left(r_{1}-1\right)^{2}}, & \text { for } j=1,\end{cases}
$$

where $r_{j}$ is the sample autocorrelation coefficient for lag (order) $-j$, calculated by

$$
r_{j}=\frac{(1 /(n-j)) \sum_{i=1}^{n-j}\left(P_{i}-\bar{P}\right)\left(P_{i+j}-\bar{P}\right)}{(1 / n) \sum_{i=1}^{n}\left(P_{i}-\bar{P}\right)^{2}}, \quad j=1,2, \ldots, \frac{n}{4},
$$

where $\bar{P}$ is the average value of all $P_{i}$ in the data sets and $n$ is year number. If $r_{j}$ falls inside the confidence limits, the hypothesis that $r_{j}$ is zero is accepted using a two-tailed test. The lower and upper limits of $r_{j}$ at a confidence level of $95 \%$ are estimated as follows:

$$
\mathrm{CL}\left(r_{j}\right)(\alpha=0.05)=\frac{-1 \pm 1.96 \sqrt{n-j-1}}{n-j} .
$$

The magnitude of the slope of the trend is estimated according to Sen [53]. Sen's slope (b) is a robust estimate of the magnitude of monotonic trend and is calculated as [50]:

$$
b=\operatorname{Median}\left(\frac{P_{j}-P_{i}}{j-i}\right) \quad \forall i<j .
$$

\section{Results}

3.1. Spatial Distributions and Trends of Annual Mean $E T_{o}$, $P$, and DI Over 1961-2010. A total of 41 weather stations in Xinjiang, China, with observed datasets over 1961-2000 were selected. The longitude and latitude ranges of the 41 sites were between E36.9 and $48.1^{\circ}$ and N75.2 and $94.7^{\circ}$, respectively. The elevation $n$ varied from 30 to $3095 \mathrm{~m}$. The basic geological locations and elevations of the selected sites are demonstrated in Figure 1.

Takelamagan desert was located in the middle south part of the region; there were sparse weather stations located within the desert zone. The annual mean weather conditions of the 41 sites are given in Table 1.

Figure 2 shows the spatial variations of the multiyear average values for the main climatic elements in Xinjiang including hours of sunshine $(\bar{N})$, air temperature $(\bar{T})$, relative humidity $(\overline{\mathrm{RH}})$, and wind speed $(\bar{U}) \cdot \bar{N}$ generally increased from the west to the east part of the region. $\bar{T}$ generally decreased from the south to the north of the region with higher temperatures located in the desert zone and the site with low elevation (Tulufan). $\overline{\mathrm{RH}}$ decreased from the north to the south of the region. $\bar{U}$ generally decreased from the east to the west of the region.

The spatial distributions of annual mean precipitation $\left(P_{\mathrm{AM}}\right), \mathrm{ET}_{o, \mathrm{AM}}$, and $\mathrm{DI}_{\mathrm{AM}}$ estimated from the historical observed weather data are illustrated in Figure 3.

Overall decreasing distributions of $P_{\mathrm{AM}}$ and $\mathrm{DI}_{\mathrm{AM}}$ and increasing distributions of $\mathrm{ET}_{O, \mathrm{AM}}$ from north to south were observed. Larger $P_{\mathrm{AM}}$ was found in mountain areas. $P_{\mathrm{AM}}$ increased with increased elevations. $P_{\mathrm{AM}}$ ranged between 0.004 and $1.36 \mathrm{~mm}^{-1}{ }^{-1}, \mathrm{ET}_{o, \mathrm{AM}}$ ranged between 1.52 and $3.42 \mathrm{~mm}$ day $^{-1}$, and $\mathrm{DI}_{\mathrm{AM}}$ ranged between 1.5 (at Yining) and 479.6 (at Ruoqiang). $\mathrm{DI}_{\mathrm{AM}}$ exhibited a large variability in space. The largest $\mathrm{DI}_{\mathrm{AM}}$ was at Ruoqiang, with Tulufan, Minfeng, Qiemo, Hetian, and Bachu also having large $\mathrm{DI}_{\mathrm{AM}}$ values (>100), indicating high extent of droughts. $\mathrm{DI}_{\mathrm{AM}}$ values at Aheqi, Balikun, Hebukesaier, Tacheng, Qitai, Shihezi, Tuoli, and Wusu were less than 12. Over 1960-2010; $\mathrm{DI}_{\mathrm{AM}}$ in the whole region $\left(\mathrm{DI}_{\mathrm{WR}}\right)$ could be estimated using the historical $\mathrm{DI}_{\mathrm{AM}}$ and the obtained $A_{W}$ of each site (Table 2). 
TABLE 1: Basic information of meteorological stations. $\bar{T}, \overline{\mathrm{RH}}, \bar{U}$, and $\bar{N}$ are multiyear mean air temperature, relative humidity, wind speed, and sunshine hour, respectively.

\begin{tabular}{|c|c|c|c|c|c|c|c|c|}
\hline Site & Longitude $\left({ }^{\circ}\right)$ & Latitude $\left({ }^{\circ}\right)$ & Elevation & $\bar{T}\left({ }^{\circ} \mathrm{C}\right)$ & $\bar{U}\left(\mathrm{~m} \mathrm{~s}^{-1}\right)$ & $\overline{\mathrm{RH}}(\%)$ & $\bar{N}(\mathrm{~h})$ & $P\left(\mathrm{~mm} \mathrm{day}^{-1}\right)$ \\
\hline Tulufan & 89.2 & 42.9 & 30 & 14.5 & 1.3 & 40.6 & 8.1 & 0.04 \\
\hline Jinghe & 82.9 & 44.6 & 304 & 7.8 & 1.7 & 61.3 & 7.1 & 0.24 \\
\hline Kelamayi & 85.0 & 45.6 & 329 & 8.6 & 3.2 & 48.3 & 7.4 & 0.28 \\
\hline Shihezi & 86.2 & 44.3 & 470 & 7.2 & 1.5 & 64.5 & 7.5 & 0.49 \\
\hline Fuhai & 87.5 & 47.1 & 498 & 4.1 & 2.6 & 62.4 & 7.9 & 0.30 \\
\hline Habahe & 86.4 & 48.1 & 539 & 4.8 & 4.0 & 60.6 & 8.3 & 0.45 \\
\hline Tacheng & 83.0 & 46.8 & 550 & 6.9 & 2.3 & 60.3 & 8.1 & 0.67 \\
\hline Wusu & 84.7 & 44.5 & 684 & 8.1 & 2.2 & 58.5 & 7.4 & 0.41 \\
\hline Hami & 93.5 & 42.8 & 763 & 10.0 & 2.2 & 43.0 & 9.1 & 0.10 \\
\hline Yining & 81.5 & 44.0 & 790 & 8.9 & 1.9 & 65.5 & 7.8 & 0.66 \\
\hline Urumqi & 87.6 & 43.8 & 836 & 6.9 & 2.4 & 58.2 & 7.3 & 0.64 \\
\hline Ruoqiang & 88.2 & 39.0 & 895 & 11.9 & 2.6 & 39.4 & 8.4 & 0.08 \\
\hline Aletai & 88.1 & 47.8 & 939 & 4.5 & 2.4 & 57.6 & 8.2 & 0.46 \\
\hline Tuoli & 83.6 & 46.0 & 946 & 5.3 & 2.9 & 56.3 & 7.7 & 0.58 \\
\hline Kuerle & 86.2 & 41.8 & 948 & 11.8 & 2.5 & 45.3 & 7.9 & 0.15 \\
\hline Jimunai & 85.9 & 47.4 & 951 & 4.2 & 3.8 & 57.2 & 8.0 & 0.50 \\
\hline Luntai & 84.3 & 41.8 & 982 & 11.1 & 1.3 & 49.3 & 7.4 & 0.19 \\
\hline Bohu & 86.6 & 42.0 & 1057 & 8.5 & 1.9 & 56.8 & 8.3 & 0.20 \\
\hline Kuche & 83.0 & 41.7 & 1071 & 11.4 & 2.3 & 45.4 & 7.7 & 0.18 \\
\hline Akesu & 80.3 & 41.2 & 1106 & 10.4 & 1.6 & 57.3 & 7.8 & 0.19 \\
\hline Bachu & 78.6 & 39.8 & 1119 & 12.1 & 1.6 & 48.0 & 7.8 & 0.15 \\
\hline Keping & 79.1 & 40.5 & 1161 & 11.7 & 1.7 & 44.8 & 7.5 & 0.24 \\
\hline Shache & 77.3 & 38.4 & 1233 & 11.7 & 1.5 & 53.7 & 7.9 & 0.14 \\
\hline Baicheng & 81.9 & 41.8 & 1236 & 7.9 & 0.8 & 63.9 & 7.9 & 0.30 \\
\hline Qieme & 85.5 & 38.2 & 1246 & 10.6 & 1.9 & 41.7 & 7.7 & 0.08 \\
\hline Qitai & 90.4 & 45.2 & 1278 & 5.2 & 3.1 & 60.8 & 8.2 & 0.45 \\
\hline Hebukesaier & 85.7 & 46.8 & 1293 & 3.7 & 2.6 & 53.6 & 8.0 & 0.36 \\
\hline Fuyun & 89.5 & 47.0 & 1304 & 3.1 & 1.8 & 59.2 & 7.9 & 0.42 \\
\hline Shufu & 75.9 & 39.4 & 1331 & 11.9 & 1.9 & 50.8 & 7.6 & 0.16 \\
\hline Pishan & 78.3 & 37.6 & 1373 & 12.2 & 1.5 & 44.1 & 7.1 & 0.13 \\
\hline Hetian & 79.8 & 37.1 & 1388 & 12.6 & 1.9 & 42.1 & 7.2 & 0.10 \\
\hline Minfeng & 82.7 & 37.1 & 1416 & 11.6 & 1.6 & 41.1 & 7.9 & 0.10 \\
\hline Yutian & 81.7 & 36.9 & 1432 & 11.7 & 1.5 & 45.0 & 7.7 & 0.13 \\
\hline Balikun & 93.0 & 43.6 & 1632 & 1.9 & 2.4 & 56.2 & 8.5 & 0.53 \\
\hline Wenquan & 81.1 & 44.9 & 1697 & 3.9 & 2.2 & 64.6 & 7.5 & 0.75 \\
\hline Qinghe & 90.4 & 46.7 & 1730 & 0.7 & 1.3 & 60.6 & 8.5 & 0.40 \\
\hline Zhaosu & 81.1 & 43.2 & 1890 & 3.3 & 2.3 & 67.4 & 7.3 & 0.13 \\
\hline Aheqi & 78.5 & 40.9 & 1990 & 6.6 & 2.7 & 50.0 & 7.8 & 0.55 \\
\hline Yiwu & 94.7 & 43.3 & 1995 & 3.9 & 3.5 & 42.0 & 8.9 & 0.28 \\
\hline Wuqia & 75.3 & 39.7 & 2181 & 7.3 & 2.4 & 45.6 & 7.8 & 0.43 \\
\hline Tashikuergan & 75.2 & 37.8 & 3095 & 3.6 & 2.0 & 39.9 & 7.9 & 0.17 \\
\hline
\end{tabular}

The estimated historical mean $\mathrm{DI}_{\mathrm{WR}}$ was 16.0; thus Xinjiang should generally be an arid region according to Arora [8].

The calculated MK statistics $Z$ and the MMK statistics $Z^{*}$ for $P_{\mathrm{AM}}, \mathrm{ET}_{o, \mathrm{AM}}$, and $\mathrm{DI}_{\mathrm{AM}}$ over 1961-2000 are given in Table 3.

In Table 3, (1) there were general increasing trends in $\mathrm{ET}_{o, \mathrm{AM}} \cdot \mathrm{ET}_{o, \mathrm{AM}}$ series at 11 sites were temporally independent with the order of the autocorrelation coefficient $j$ being equal to 0 . The trends in series $\mathrm{ET}_{o, \mathrm{AM}}$ at 11 sites increased significantly both by the MK and MKK tests at a confidence level of $95 \%$. The trends in $\mathrm{ET}_{o, \mathrm{AM}}$ at 26 sites were tested significantly by the MK method but insignificantly at 15 out of 26 sites by the MMK method when $j$ ranged from 1 to 8 . The existence of serial autocorrelation structures changed, in other words, decreased the significance of the trends, especially at high orders $(j)$ of $r_{j}$. Consideration of serial 


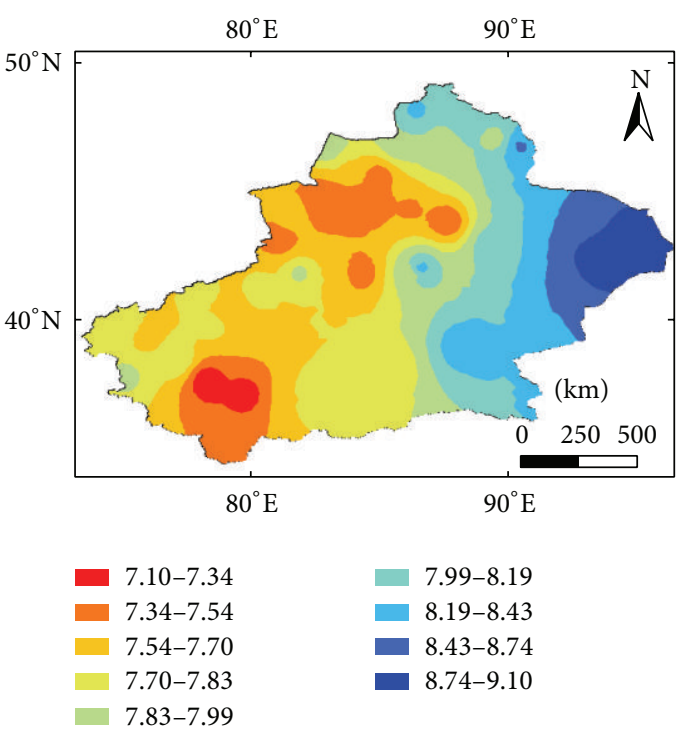

(a) Sunshine hour

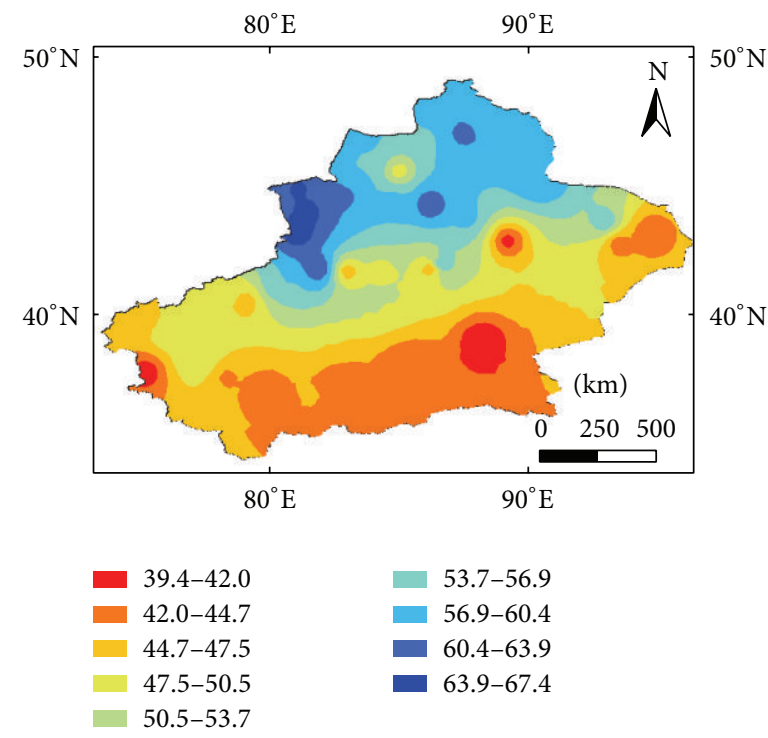

(c) Relative humidity (\%)

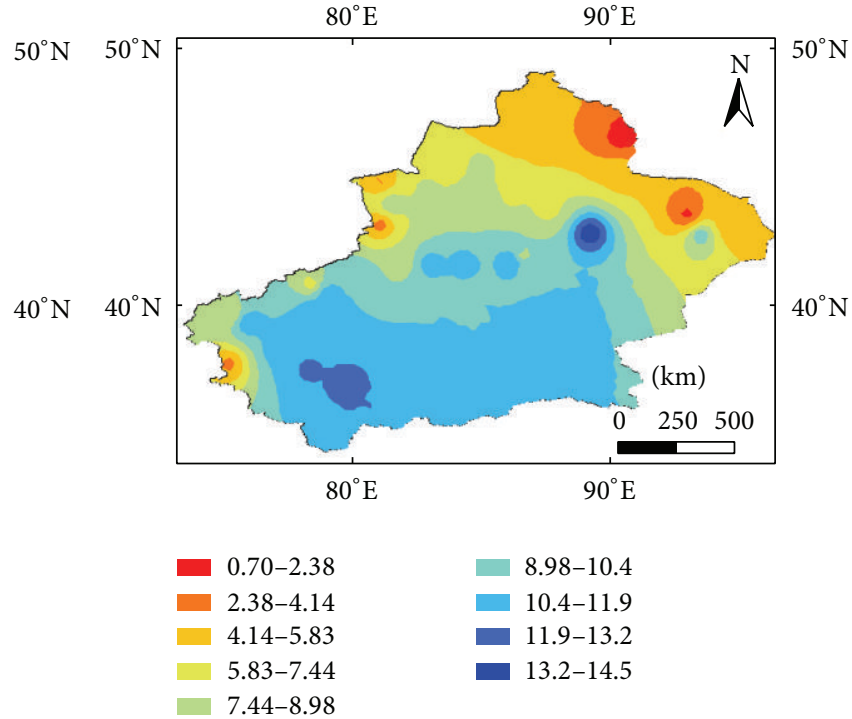

(b) Air temperature $\left({ }^{\circ} \mathrm{C}\right)$

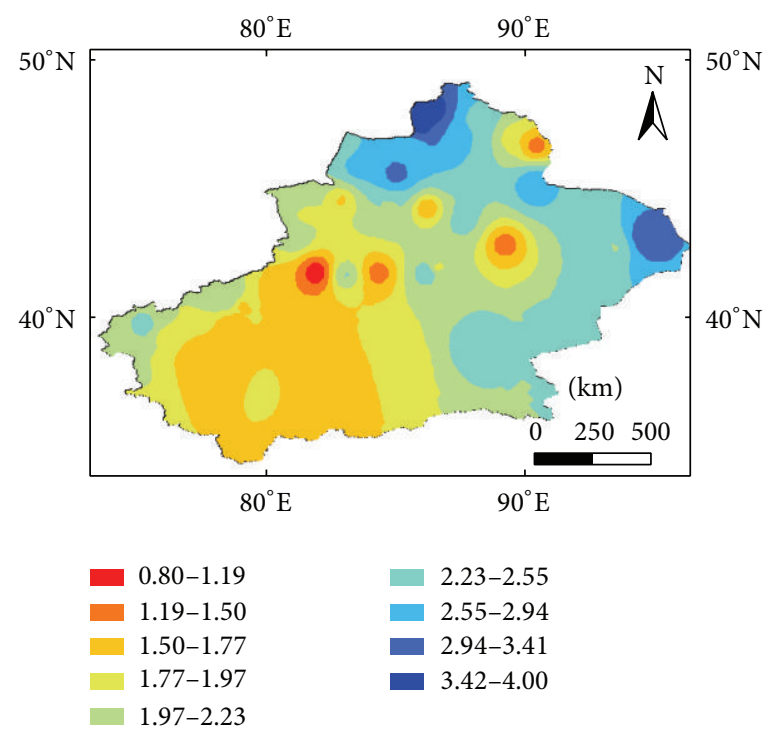

(d) Wind speed $(\mathrm{m} / \mathrm{s})$

FIGURE 2: Spatial distributions of the multiyear mean climatic elements in the study region.

autocorrelation structures was necessary when performing trend tests, in case the trends were exaggerated. For consistency, the final trend test results should adopt $Z$ values when $j=0$ from MK test and $Z^{*}$ values when $j>0$ from MKK test, so that the tested trends considering the limitations of serial autocorrelation. By this principle, the trends in $\mathrm{ET}_{o, \mathrm{AM}}$ at 6 sites increased significantly and trends at 1 site decreased significantly. Overall, the trends in $\mathrm{ET}_{o, \mathrm{AM}}$ increased significantly at 9 sites, increased insignificantly at 18 sites, decreased significantly at 3 sites, and decreased insignificantly at 11 sites. Sen's slope $(b)$ values of $\mathrm{ET}_{o, \mathrm{AM}}$ ranged from -0.005 to 0.006 for different sites (data not shown), which corresponded with the trends in the data series, also indicating that values of $b$ were generally low when the trends were insignificant. (2) $P_{\mathrm{AM}}$ series at 20 sites were temporally independent $(j=0)$. The trends in $P_{\mathrm{AM}}$ at all sites increased. The trends in $P_{\mathrm{AM}}$ at 29 sites were significant using the MK method but trends at only 16 sites were significant by the MMK method when $j$ ranged from 1 to 9. Overall, the trends in $P_{\mathrm{AM}}$ at 13 sites increased significantly. Sen's slope $(b)$ values of $P_{\mathrm{AM}}$ ranged from 0.001 to 0.009 for the various sites. (3) Similarly, $\mathrm{DI}_{\mathrm{AM}}$ series at 23 sites were temporally independent. The trends in $\mathrm{DI}_{\mathrm{AM}}$ at 40 out of 41 sites decreased. The trends in $\mathrm{DI}_{\mathrm{AM}}$ at 29 sites tested significant using the MK method but trends at 9 out of 29 sites tested insignificant by the MMK method when $j$ ranged from 1 to 10. Overall, the trends in $\mathrm{DI}_{\mathrm{AM}}$ at 21 sites decreased significantly. Sen's slope $(b)$ values of $\mathrm{DI}_{\mathrm{AM}}$ ranged from 


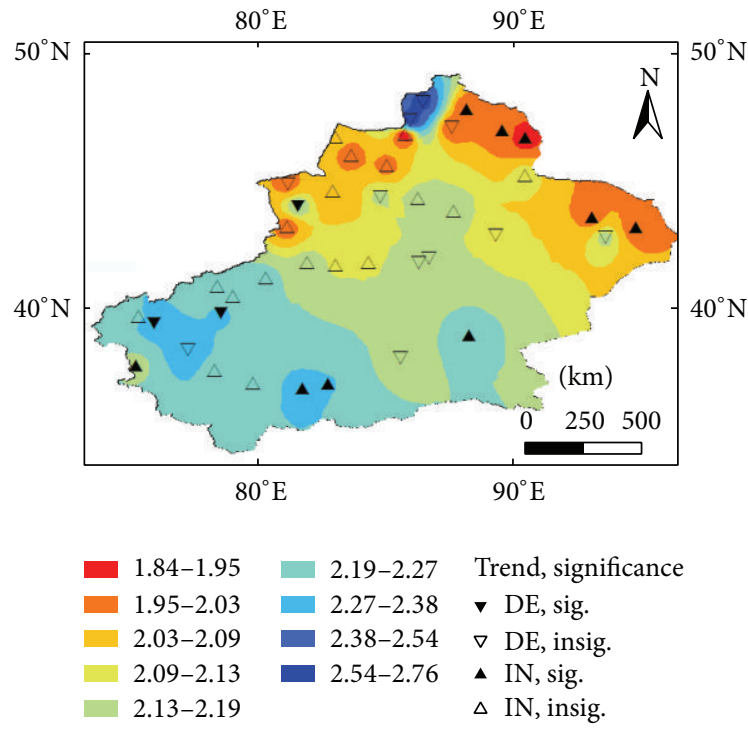

(a) $\mathrm{ET}_{o, \mathrm{AM}}$
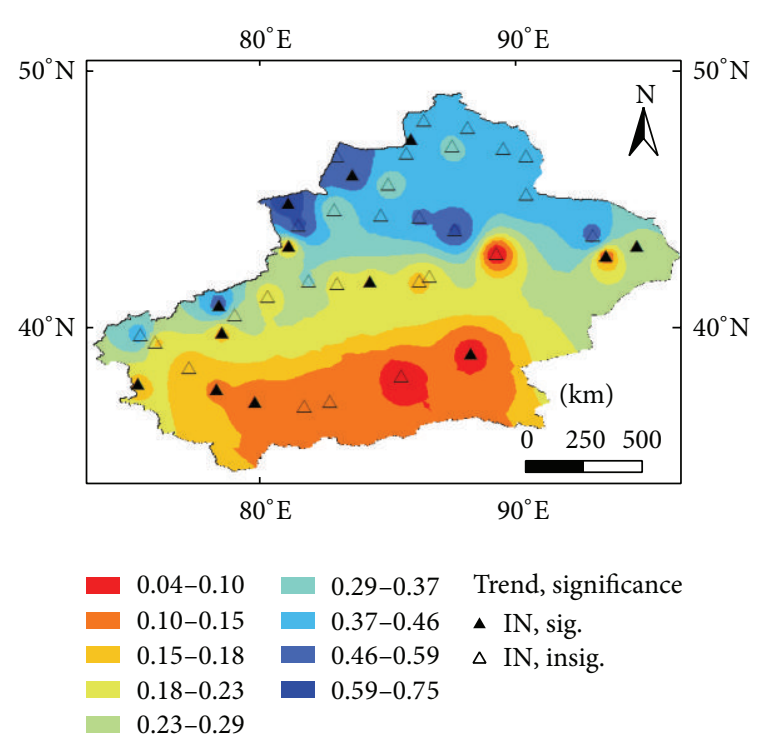

(b) $P_{\mathrm{AM}}$

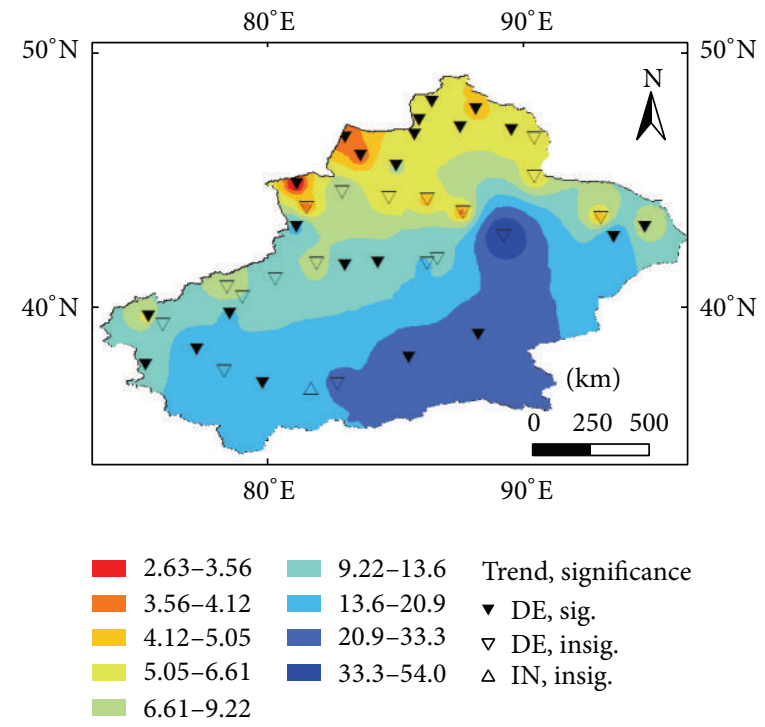

(c) $\mathrm{DI}_{\mathrm{AM}}$

FIgURE 3: Spatial distributions and trends of $\mathrm{ET}_{o, \mathrm{AM}}, P_{\mathrm{AM}}$, and $\mathrm{DI}_{\mathrm{AM}}$ over 1961-2010 in Xinjiang. DE: decrease, IN: increase, sig.: significant at a $95 \%$ confidence level, insig.: insignificant at a 95\% confidence level (similar below).

-0.755 to 0.022 for the various sites. A general decrease in $\mathrm{DI}_{\mathrm{AM}}$ showed a humid signal in drought evolution over 19602010 , caused by increased $P_{\mathrm{AM}}$ in the region.

The spatial distributions of the final trends (using the combined $\mathrm{MK}$ and MMK test results) for $P_{\mathrm{AM}}, \mathrm{ET}_{o, \mathrm{AM}}$, and $\mathrm{DI}_{\mathrm{AM}}$ of each site are visually shown in Figure 3. There were obvious differences.

\subsection{Projection of Daily Precipitation and ET $T_{o}$ over 2015-2099 Using SDSM}

3.2.1. Calibration and Validation of the Regressions for Daily $P$ and $E T_{o}$. Predictors were selected for the region (Table 4) so that regression functions could be established when using the SDSM 4.2 software. Table 4 shows that (1) daily $P$ series were related to $500 \mathrm{hPa}$ geopotential height at 29 out of 41 sites, to surface velocity at 24 sites, to $500 \mathrm{hPa}$ velocity at 24 sites, to $500 \mathrm{hPa}$ meridional velocity at 19 sites, and to relative humidity at 17 sites. In total, 21 predictors were related to daily $P$ at a minimum of 1 site. (2) Daily $\mathrm{ET}_{o}$ series were highly correlated to mean temperature at $2 \mathrm{~m}$ for all of the selected sites, to surface specific humidity at 25 sites, to $500 \mathrm{hPa}$ geopotential height at 20 sites, to $850 \mathrm{hPa}$ relative humidity at 14 sites, to mean sea level pressure at 13 sites, and to surface velocity at 12 sites. 15 predictors were related to daily $\mathrm{ET}_{o}$ at a minimum of 1 site and a maximum of 
TABle 2: Area weights $\left(A_{W}\right)$ of the studied sites in Xinjiang, China.

\begin{tabular}{|c|c|}
\hline Site & $A_{W}$ \\
\hline Aheqi & 0.0133 \\
\hline Akesu & 0.0306 \\
\hline Aletai & 0.0121 \\
\hline Bachu & 0.0216 \\
\hline Balikun & 0.0338 \\
\hline Baicheng & 0.0220 \\
\hline Bohu & 0.0237 \\
\hline Fuhai & 0.0201 \\
\hline Fuyun & 0.0173 \\
\hline Habahe & 0.0094 \\
\hline Hami & 0.0542 \\
\hline Hebukesaier & 0.0121 \\
\hline Hetian & 0.0537 \\
\hline Jimunai & 0.0047 \\
\hline Jinghe & 0.0197 \\
\hline Kalamayi & 0.0132 \\
\hline Keping & 0.0132 \\
\hline Kuche & 0.0305 \\
\hline Kuerle & 0.0257 \\
\hline Luntai & 0.0328 \\
\hline Minfeng & 0.0539 \\
\hline Pishan & 0.0382 \\
\hline Qiemo & 0.0780 \\
\hline Qinghe & 0.0087 \\
\hline Qitai & 0.0301 \\
\hline Ruoqiang & 0.1210 \\
\hline Shache & 0.0221 \\
\hline Shihezi & 0.0220 \\
\hline Shufu & 0.0166 \\
\hline Tacheng & 0.0057 \\
\hline Tashikuergan & 0.0231 \\
\hline Tulufan & 0.0615 \\
\hline Tuoli & 0.0127 \\
\hline Urumqi & 0.0275 \\
\hline Wenquan & 0.0088 \\
\hline Wuqia & 0.0183 \\
\hline Wusu & 0.0197 \\
\hline Yining & 0.0109 \\
\hline Yiwu & 0.0285 \\
\hline Yutian & 0.0352 \\
\hline
\end{tabular}

11 sites. (3) Both daily $P$ and $\mathrm{ET}_{o}$ series were not related to $500 \mathrm{hPa}$ divergence, $850 \mathrm{hPa}$ geopotential height, $850 \mathrm{hPa}$ wind direction, and $850 \mathrm{hPa}$ divergence at any site.

The observed historical daily $P, \mathrm{ET}_{o}$, and the NCEP reanalysis data were used for establishing the regression equations over the calibration period of 1961-1990 for each site using the SDSM software. Then the NCEP reanalysis data over the validation period of 1991-2000 were input to the established equations to simulate daily $P$ and $\mathrm{ET}_{o}$ series, which would be compared with the observed data
TABLE 3: Trend detection results over 1961-2010.

\begin{tabular}{|c|c|c|c|c|c|c|}
\hline \multirow{2}{*}{ Site } & \multicolumn{2}{|c|}{$\mathrm{ET}_{o, \mathrm{AM}}$} & \multicolumn{2}{|c|}{$P_{\mathrm{AM}}$} & \multicolumn{2}{|c|}{$\mathrm{DI}_{\mathrm{AM}}$} \\
\hline & $Z$ & $Z^{*}(j)$ & $Z$ & $Z^{*}(j)$ & $Z$ & $Z^{*}(j)$ \\
\hline Aheqi & 1.27 & & $3.32^{*}$ & $2.58^{*}(1)$ & $-3.35^{*}$ & $-1.44(10)$ \\
\hline Akesu & $2.76^{*}$ & $1.70(2)$ & 1.27 & $0.84(1)$ & -1.29 & $-0.95(1)$ \\
\hline Aletai & $4.13^{*}$ & $2.73^{*}(1)$ & $4.64^{*}$ & $1.55(9)$ & $-4.60^{*}$ & $-2.74^{*}(3)$ \\
\hline Bachu & $-2.88^{*}$ & & $2.19^{*}$ & & $-2.44^{*}$ & \\
\hline Baicheng & $3.98^{*}$ & $1.44(8)$ & $2.386^{*}$ & $1.37(1)$ & $-3.65^{*}$ & $-1.89(4)$ \\
\hline Balikun & $3.75^{*}$ & $2.67^{*}(2)$ & $3.98^{*}$ & $1.58(8)$ & -1.95 & $-1.41(1)$ \\
\hline Bohu & -0.65 & $-0.50(1)$ & 1.11 & & -1.15 & \\
\hline Fuhai & -0.40 & & $2.359^{*}$ & $1.78(1)$ & $-2.38^{*}$ & \\
\hline Fuyun & $6.54^{*}$ & $2.92^{*}(5)$ & $4.27^{*}$ & $1.46(8)$ & $-3.81^{*}$ & $-2.05^{*}(3)$ \\
\hline Habahe & $-2.49^{*}$ & $-1.78(1)$ & $4.32^{*}$ & $1.81(7)$ & $-4.25^{*}$ & \\
\hline Hami & $-4.25^{*}$ & $-1.67(8)$ & $3.681^{*}$ & & $-3.76^{*}$ & \\
\hline Hebukesaier & 0.42 & & 1.36 & & $-1.99^{*}$ & \\
\hline Hetian & 1.74 & $1.10(2)$ & $2.02^{*}$ & & $-1.99^{*}$ & \\
\hline Jimunai & -0.82 & $-0.58(1)$ & $4.35^{*}$ & $2.03^{*}(4)$ & $-4.08^{*}$ & $-2.04^{*}(4)$ \\
\hline Jinghe & 1.42 & $0.99(1)$ & 1.87 & & -1.87 & \\
\hline Kelamayi & $2.76^{*}$ & $1.70(2)$ & $2.61^{*}$ & $1.62(3)$ & -1.51 & \\
\hline Keping & 1.51 & $1.17(1)$ & 1.46 & & $-2.74^{*}$ & \\
\hline Kuche & 1.36 & $0.79(2)$ & $2.46^{*}$ & $1.68(2)$ & $-2.39^{*}$ & \\
\hline Kuerle & $-2.29^{*}$ & $-1.43(1)$ & 1.10 & & -1.29 & \\
\hline Luntai & $2.07^{*}$ & $1.67(1)$ & $4.90^{*}$ & $2.28^{*}(5)$ & $-5.02^{*}$ & $-2.31^{*}(6)$ \\
\hline Minfeng & $3.51^{*}$ & $2.49^{*}(1)$ & 1.91 & & -1.84 & \\
\hline Pishan & $4.17^{*}$ & $1.54(6)$ & $2.05^{*}$ & & -1.82 & \\
\hline Qieme & -0.87 & & $2.93^{*}$ & $1.94(2)$ & $-3.71^{*}$ & $-1.47(9)$ \\
\hline Qinghe & $3.38^{*}$ & & $3.88^{*}$ & $1.43(8)$ & $-2.84^{*}$ & \\
\hline Qitai & $2.64^{*}$ & $1.51(3)$ & $3.87^{*}$ & $1.52(9)$ & $-3.80^{*}$ & $-1.43(10)$ \\
\hline Ruoqiang & $2.89^{*}$ & $2.09^{*}(2)$ & $3.44^{*}$ & & $-3.48^{*}$ & \\
\hline Shache & -0.72 & & 1.49 & & $-4.32^{*}$ & \\
\hline Shihezi & $3.73^{*}$ & $1.57(7)$ & $3.68^{*}$ & $1.62(6)$ & $-3.53^{*}$ & $-1.95(3)$ \\
\hline Shufu & $-3.48^{*}$ & & 1.874 & & -1.81 & \\
\hline Tacheng & $2.09^{*}$ & $-1.51(1)$ & $3.61^{*}$ & $1.63(6)$ & $-3.93^{*}$ & $-2.39^{*}(3)$ \\
\hline Tashikuergan & $4.20^{*}$ & $1.97^{*}(7)$ & $2.91^{*}$ & & $-2.64^{*}$ & \\
\hline Tulufan & -1.00 & $-0.75(1)$ & 1.55 & & -1.57 & \\
\hline Tuoli & $2.74^{*}$ & $1.78(3)$ & $2.22^{*}$ & & $-2.09^{*}$ & \\
\hline Urumqi & $2.06^{*}$ & $1.50(3)$ & $4.63^{*}$ & $1.54(9)$ & $-3.40^{*}$ & \\
\hline Wenquan & -1.26 & $-0.99(1)$ & $3.46^{*}$ & & $-4.62^{*}$ & $-1.72(9)$ \\
\hline Wuqia & $4.18^{*}$ & $1.80(7)$ & 1.79 & & $-1.62^{*}$ & \\
\hline Wusu & -0.08 & & $3.20^{*}$ & $1.87(3)$ & $-3.21^{*}$ & $-1.76(3)$ \\
\hline Yining & $-5.44^{*}$ & $-2.85^{*}(3)$ & $3.88^{*}$ & $1.68(6)$ & $-4.28^{*}$ & $-1.64(8)$ \\
\hline Yiwu & $2.99^{*}$ & & $4.38^{*}$ & $2.55^{*}(3)$ & $-4.32^{*}$ & \\
\hline Yutian & $3.15^{*}$ & $2.18^{*}(1)$ & 0.084 & & 1.17 & 0.89 (1) \\
\hline Zhaosu & 1.15 & & $2.85^{*}$ & & $-2.34^{*}$ & \\
\hline
\end{tabular}

over 1991-2000 to validate the goodness of the established regression equations. Taking Yiwu station as an example, for daily $P$, six predictors, including surface velocity, $500 \mathrm{hPa}$ airflow strength, $500 \mathrm{hPa}$ velocity, $500 \mathrm{hPa}$ geopotential height, $850 \mathrm{hPa}$ relative humidity, and near surface relative humidity, were selected. The partial correlation coefficients between daily $P$ and the above six predictors were $-0.233,-0.175$, $0.247,0.088,0.039$, and 0.145 , respectively, at a significance level of 0.0001 . The $R^{2}$ and $E_{\mathrm{ns}}$ values for the established regression equations for predicting daily $P$ of the 41 studied sites are listed in Table 5. There were generally high $R^{2}$ (ranging from 0.877 to 0.998 ) and $E_{\mathrm{ns}}$ values (ranging from 
TABLE 4: The selected predictors used for developing a relationship between the predictand and predictor.

\begin{tabular}{|c|c|c|c|}
\hline Number & $\mathrm{PR}$ & NPP & NPE \\
\hline 1 & Mean sea level pressure & 7 & 13 \\
\hline 2 & Surface airflow strength & 2 & 3 \\
\hline 3 & Surface zonal velocity & 5 & 9 \\
\hline 4 & Surface meridional velocity & 12 & 6 \\
\hline 5 & Surface velocity & 24 & 12 \\
\hline 6 & Surface wind direction & 2 & 1 \\
\hline 7 & Surface divergence & 10 & 1 \\
\hline 8 & $500 \mathrm{hPa}$ airflow strength & 10 & 1 \\
\hline 9 & $500 \mathrm{hPa}$ zonal velocity & 13 & 3 \\
\hline 10 & $500 \mathrm{hPa}$ meridional velocity & 19 & 7 \\
\hline 11 & $500 \mathrm{hPa}$ velocity & 24 & 1 \\
\hline 12 & $500 \mathrm{hPa}$ geopotential height & 29 & 20 \\
\hline 13 & $500 \mathrm{hPa}$ wind direction & 0 & 0 \\
\hline 14 & $500 \mathrm{hPa}$ divergence & 0 & 0 \\
\hline 15 & $850 \mathrm{hPa}$ airflow strength & 1 & 2 \\
\hline 16 & $850 \mathrm{hPa}$ zonal velocity & 9 & 10 \\
\hline 17 & $850 \mathrm{hPa}$ meridional velocity & 8 & 8 \\
\hline 18 & $850 \mathrm{hPa}$ velocity & 6 & 7 \\
\hline 19 & $850 \mathrm{hPa}$ geopotential height & 0 & 0 \\
\hline 20 & $850 \mathrm{hPa}$ wind direction & 0 & 0 \\
\hline 21 & $850 \mathrm{hPa}$ divergence & 0 & 0 \\
\hline 22 & $500 \mathrm{hPa}$ relative humidity & 17 & 5 \\
\hline 23 & $850 \mathrm{hPa}$ relative humidity & 17 & 14 \\
\hline 24 & Near surface relative humidity & 8 & 8 \\
\hline 25 & Surface specific humidity & 1 & 25 \\
\hline 26 & Mean temperature at $2 \mathrm{~m}$ & 6 & 41 \\
\hline
\end{tabular}

PR: Predictor, NPP and NPE: numbers of stations used for establishing predictor-predictand relationship of rainfall and $\mathrm{ET}_{o}$.

0.566 to 0.988 ) for the selected 41 sites. The same procedure was used to predict daily $\mathrm{ET}_{o}$ at the 41 chosen sites in the region. The established regression functions for predicting daily $P$ and $\mathrm{ET}_{o}$ in 2015-2099 in this region were generally good and could be used for projecting future daily $P$ and $\mathrm{ET}_{o}$ data using a weather generator.

\subsubsection{Projected Daily $P$ and $E T_{o}$ Using SDSM and Generated} DI over 2015-2099. Daily $P$ and $\mathrm{ET}_{o}$ data over 2015-2099 were projected under $\mathrm{A} 2$ and $\mathrm{B} 2$ scenarios for the 41 sites using SDSM version 4.2. Daily DI values over 2015-2099 were estimated according to the projected daily $P$ and $\mathrm{ET}_{o}$ data. $P_{\mathrm{AM}}, \mathrm{ET}_{o, \mathrm{AM}}$, and $\mathrm{DI}_{\mathrm{AM}}$ were then estimated based on the projected daily $P$ and $\mathrm{ET}_{o}$ data. Spatial distributions and the tested trends of $P_{\mathrm{AM}}, \mathrm{ET}_{o, \mathrm{AM}}$, and $\mathrm{DI}_{\mathrm{AM}}$ over 2015-2099 in Xinjiang are illustrated in Figure 4.

$\mathrm{ET}_{o, \mathrm{AM}}$ over 2015-2099 ranged between 1.77 and $2.71 \mathrm{~mm} \mathrm{day}^{-1}$ under scenario A2 and between 1.65 and $2.72 \mathrm{~mm} \mathrm{day}^{-1}$ under scenario B2. $P_{\mathrm{AM}}$ over 2015-2099 ranged between 0.04 and $0.62 \mathrm{~mm} \mathrm{day}^{-1}$ under scenario A2 and between 0.03 and $0.65 \mathrm{~mm} \mathrm{day}^{-1}$ under scenario $\mathrm{B} 2$, which were generally larger than the historical $P_{\mathrm{AM}}$
TABle 5: Determination of coefficients $\left(R^{2}\right)$ and Nash-Suttcliffe coefficients $\left(E_{\mathrm{ns}}\right)$ for prediction of rainfall at the selected 41 sites in the validation period (1991-2000).

\begin{tabular}{|c|c|c|}
\hline Site & $R^{2}$ & $E_{\mathrm{ns}}$ \\
\hline Aheqi & 0.992 & 0.923 \\
\hline Akesu & 0.945 & 0.984 \\
\hline Aletai & 0.998 & 0.984 \\
\hline Bachu & 0.979 & 0.924 \\
\hline Balikun & 0.989 & 0.970 \\
\hline Baicheng & 0.987 & 0.786 \\
\hline Bohu & 0.969 & 0.865 \\
\hline Fuhai & 0.997 & 0.988 \\
\hline Fuyun & 0.962 & 0.910 \\
\hline Habahe & 0.993 & 0.971 \\
\hline Hami & 0.911 & 0.566 \\
\hline Hebukesaier & 0.989 & 0.978 \\
\hline Hetian & 0.962 & 0.914 \\
\hline Jimunai & 0.990 & 0.968 \\
\hline Jinghe & 0.994 & 0.936 \\
\hline Kalamayi & 0.998 & 0.968 \\
\hline Keping & 0.970 & 0.793 \\
\hline Kuche & 0.951 & 0.799 \\
\hline Kuerle & 0.973 & 0.738 \\
\hline Luntai & 0.988 & 0.914 \\
\hline Minfeng & 0.877 & 0.520 \\
\hline Pishan & 0.888 & 0.752 \\
\hline Qiemo & 0.950 & 0.873 \\
\hline Qinghe & 0.993 & 0.971 \\
\hline Qitai & 0.882 & 0.761 \\
\hline Ruoqiang & 0.955 & 0.627 \\
\hline Shache & 0.928 & 0.808 \\
\hline Shihezi & 0.994 & 0.978 \\
\hline Shufu & 0.896 & 0.765 \\
\hline Tacheng & 0.951 & 0.867 \\
\hline Tashikuergan & 0.995 & 0.942 \\
\hline Tulufan & 0.991 & 0.765 \\
\hline Tuoli & 0.986 & 0.950 \\
\hline Urumqi & 0.993 & 0.975 \\
\hline Wenquan & 0.996 & 0.989 \\
\hline Wuqia & 0.988 & 0.935 \\
\hline Wusu & 0.985 & 0.941 \\
\hline Yining & 0.992 & 0.969 \\
\hline Yiwu & 0.987 & 0.959 \\
\hline Yutian & 0.969 & 0.719 \\
\hline Zhaosu & 0.972 & 0.798 \\
\hline
\end{tabular}

over 1961-2010. Similarly to the distributions of historical data, $P_{\mathrm{AM}}$ over 2015-2099 decreased from north to south in the study region. $\mathrm{DI}_{\mathrm{AM}}$ over 2015-2099 ranged between 1.9 and 198.5 under scenario A2 and between 1.6 and 130.4 under scenario B2, generally decreasing in maximal values compared to $\mathrm{DI}_{\mathrm{AM}}$ values over 1961-2010. The $\mathrm{DI}_{\mathrm{AM}}$ values for the period of 2015-2099 showed lower potential for 

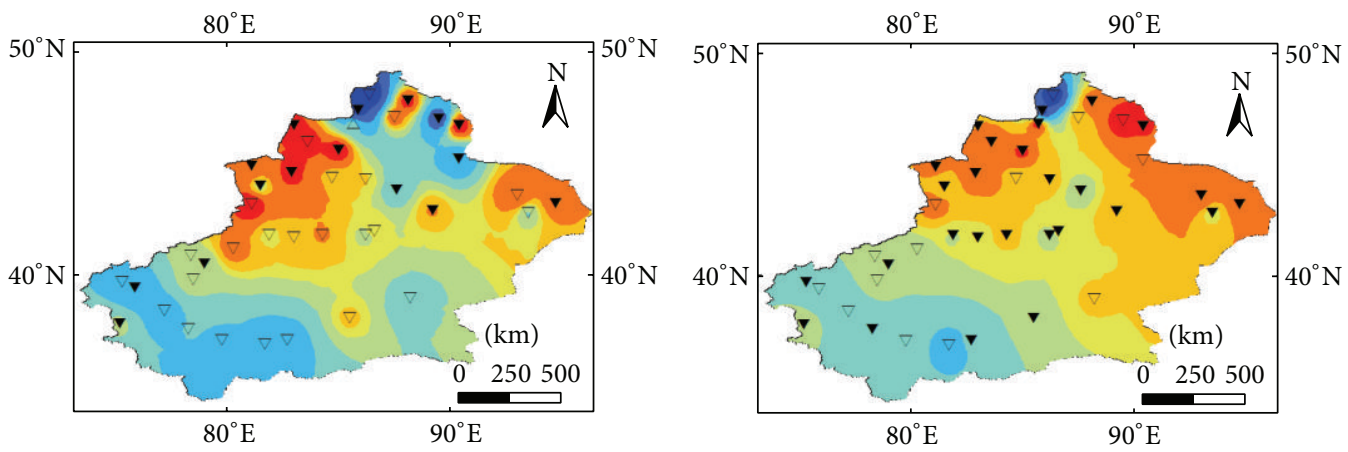

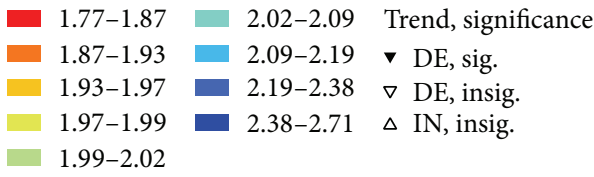

(a) Scenario A2 for $\mathrm{ET}_{o, \mathrm{AM}}$
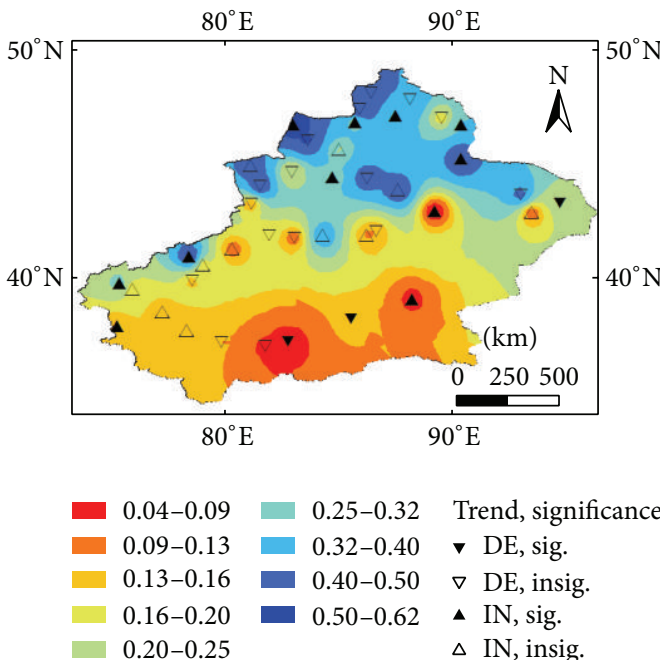

(c) Scenario A2 for $P_{\mathrm{AM}}$
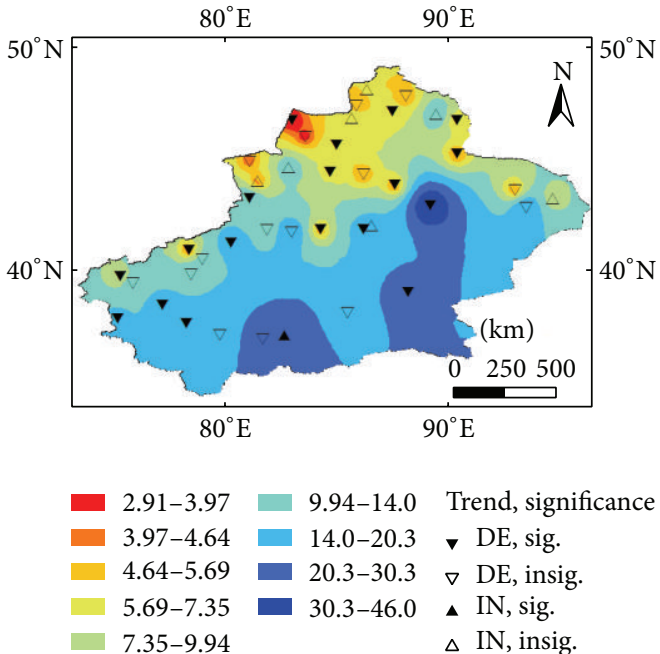

(e) Scenario A2 for $\mathrm{DI}_{\mathrm{AM}}$

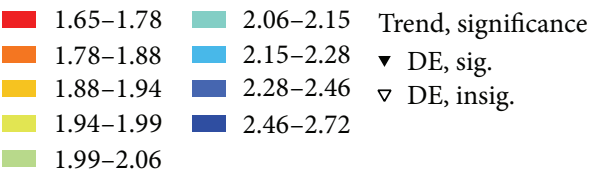

(b) Scenario $\mathrm{B} 2$ for $\mathrm{ET}_{o}$,AM
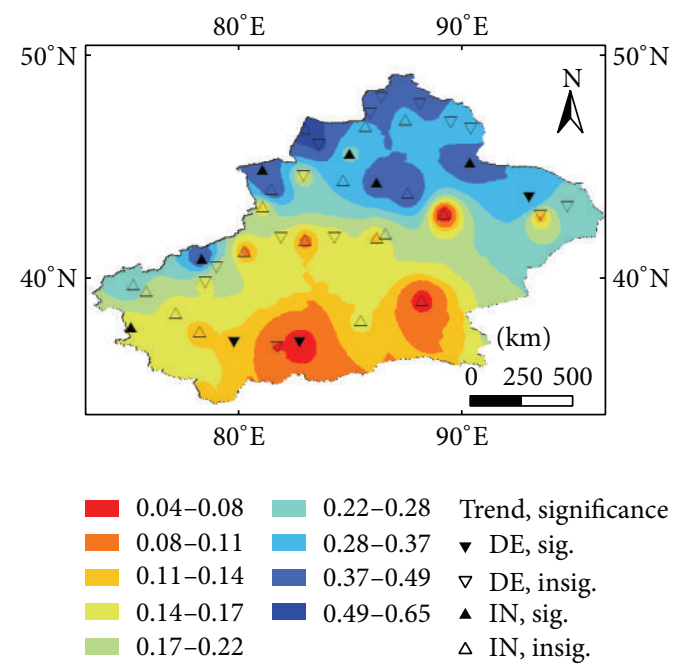

(d) Scenario B2 for $P_{\mathrm{AM}}$
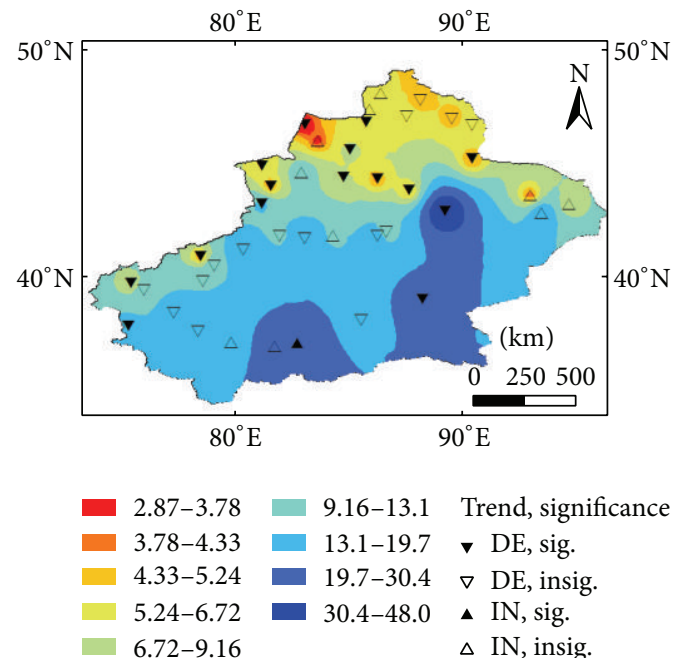

(f) Scenario B2 for $\mathrm{DI}_{\mathrm{AM}}$

FIgURE 4: Spatial distributions and the trend test results for $P_{\mathrm{AM}}, \mathrm{ET}_{o, \mathrm{AM}}$, and $\mathrm{DI}_{\mathrm{AM}}$ over 2015-2099. 
TABLE 6: Trend detection results of $P, \mathrm{ET}_{o}$, and DI in the whole region. Period 1: 1961-2010, period 2: 2015-2099, and $b$-Sen's slope.

\begin{tabular}{|c|c|c|c|c|c|c|c|c|c|}
\hline Item & $\mathrm{ET}_{o, \mathrm{WR}}$ & $\mathrm{ET}_{o, \mathrm{WR}}$ & $\mathrm{ET}_{o, \mathrm{WR}}$ & $P_{\mathrm{WR}}$ & $P_{\mathrm{WR}}$ & $P_{\mathrm{WR}}$ & $\mathrm{DI}_{\mathrm{WR}}$ & $\mathrm{DI}_{\mathrm{WR}}$ & $\mathrm{DI}_{\mathrm{WR}}$ \\
\hline Period & 1 & 2 & 2 & 1 & 2 & 2 & 1 & 2 & 2 \\
\hline Scenario & & A2 & B2 & & A2 & B2 & & A2 & B2 \\
\hline$b$ & -0.003 & -0.003 & -0.002 & 0.003 & 0.002 & 0 & -0.096 & -0.02 & -0.013 \\
\hline$Z$ & $-5.72^{*}$ & -1.84 & -1.73 & $4.97^{*}$ & $2.31^{*}$ & 0.875 & $-4.43^{*}$ & $-6.20^{*}$ & $-4.31^{*}$ \\
\hline$Z^{*}(j)$ & $-1.93(10)$ & - & - & $1.56(12)$ & - & - & $-2.30^{*}(6)$ & $-1.87(15)$ & $-3.01^{*}(2)$ \\
\hline
\end{tabular}

* denotes significance at a confidence level of $95 \%$.

drought when compared to the $\mathrm{DI}_{\mathrm{AM}}$ values from 1960 to 2010.

From the trend test results of $P_{\text {AM }}$ over 2015-2099 (data not shown), there were increasing trends in $P_{\mathrm{AM}}$ at 22 out of 41 sites under scenario A2, of which half of the trends were significant. For the other 19 sites, trends in $P_{\mathrm{AM}}$ at 3 sites decreased significantly. Under scenario B2, trends in $P_{\mathrm{AM}}$ over 2015-2099 increased at 24 sites, with 6 sites having significant increasing $P_{\mathrm{AM}}$ trends. Decreasing trends were detected in 17 sites, with 3 sites having significant decreasing $P_{\text {AM }}$ trends. Moreover, there were few stations where the predicted $P_{\mathrm{AM}}$ showed autocorrelation structures. From 2015 to 2099, $P_{\mathrm{AM}}$ under scenario A2 was found autocorrelated at 6 sites, but $P_{\mathrm{AM}}$ under scenario B2 was autocorrelated at only 2 sites. Under scenario A2, high-order autocorrelations were found at Kelamayi $(j=17)$ and Wenquan $(j=20)$, and the significance of the trends in Kalamayi and Wenquan stations changed from significant to insignificant when tested by the MMK method. Under scenario B2, no high-order autocorrelation was found in $P_{\mathrm{AM}}$ series.

$\mathrm{ET}_{o, \mathrm{AM}}$ series at only 8 out of 41 sites were temporally independent. The trend test results of $\mathrm{ET}_{o, \mathrm{AM}}$ over 20152099 (data not shown) indicated that over 2015-2099 under scenario $\mathrm{A} 2$, there were decreasing trends in $\mathrm{ET}_{o, \mathrm{AM}}$ at 40 out of 41 sites, of which, with 17 sites having significant decreasing trends. There were long-range autocorrelations of $\mathrm{ET}_{o, \mathrm{AM}}$ at 32 sites, for which the order $j$ ranged from 6 to 27. Significant trends in $\mathrm{ET}_{o, \mathrm{AM}}$ tested by the MK test at 23 sites were changed to be insignificant when tested by the MMK test when $j>$ 12. The corresponding $b$ values ranged between -0.005 and 0.004. Under scenario B2 over 2015-2099; trends in $\mathrm{ET}_{o, \mathrm{AM}}$ decreased at all of the 41 sites, of which trends at 27 sites were significant. $\mathrm{ET}_{o, \mathrm{AM}}$ series at 18 out of 41 sites were temporally independent. Long-range autocorrelations of $\mathrm{ET}_{o, \mathrm{AM}}$ were also found at 17 sites under scenario $\mathrm{B} 2$, with $j$ ranging from 5 to 21 . The $b$ values ranged between -0.004 and 0 .

$\mathrm{DI}_{\mathrm{AM}}$ series at 31 out of 41 sites were temporally independent. As to the trends in $\mathrm{DI}_{\mathrm{AM}}$ over 2015-2099 (data not shown) under scenario A2, there were decreasing trends in $\mathrm{DI}_{\mathrm{AM}}$ at 32 out of 41 sites, of which, with 18 sites having significant decreasing trends. There were no longrange autocorrelations of $\mathrm{DI}_{\mathrm{AM}}$ at the other 8 out of 10 sites $(j<7)$. The $b$ values ranged between -0.231 and 0.447 . Under scenario B2 over 2015-2099, trends in $\mathrm{DI}_{\mathrm{AM}}$ decreased at 30 sites, of which trends at 16 sites were significant. $\mathrm{DI}_{\mathrm{AM}}$ series at 35 sites were temporally independent. The order for autocorrelation ranged between 2 and 8 at 5 sites. Values of $b$ ranged between -0.121 and 0.156 .
3.2.3. Variations of $E T_{o, W R}, P_{W R}$, and $D I_{W R}$ over 2015-2099. Series of $P_{\mathrm{AM}}, \mathrm{ET}_{o, \mathrm{AM}}$, and $\mathrm{DI}_{\mathrm{AM}}$ in the whole region $\left(\mathrm{ET}_{o, \mathrm{WR}}, P_{\mathrm{WR}}\right.$, and $\left.\mathrm{DI}_{\mathrm{WR}}\right)$ gave the general variations. $\mathrm{ET}_{o, \mathrm{WR}}$, $P_{\mathrm{WR}}$, and $\mathrm{DI}_{\mathrm{WR}}$ over 2015-2099 could be obtained using (3). The serial autocorrelation at a confidence level of $95 \%$ and the temporal variations of $\mathrm{ET}_{o, \mathrm{WR}}, P_{\mathrm{WR}}$, and $\mathrm{DI}_{\mathrm{WR}}$ are shown in Figure 5. In Figures 5(a), 5(c), and 5(e), values of $j$ for historical data series for $\mathrm{ET}_{o, \mathrm{WR}}, P_{\mathrm{WR}}$, and $\mathrm{DI}_{\mathrm{WR}}$ over 19612010 were less than 12; values of $j$ for $\mathrm{ET}_{o, \mathrm{WR}}$ and $P_{\mathrm{WR}}$ over 2011-2099 were all equal to 0 , indicating their temporally independent serial structures; values of $j$ for $\mathrm{DI}_{\mathrm{WR}}$ over 20112099 were 15 for scenario A2 and 2 for scenario B2, indicating $\mathrm{DI}_{\mathrm{WR}}$ was temporally dependent. In Figures 5(b), 5(d), and 5(f), decreased $\mathrm{ET}_{o, \mathrm{WR}}$ and increased $P_{\mathrm{WR}}$ over 1961-2099 were obvious.

The trend test results for $\mathrm{ET}_{o, \mathrm{WR}}, P_{\mathrm{WR}}$, and $\mathrm{DI}_{\mathrm{WR}}$ over 1961-2099 are presented in Table 6.

In Table 6 and Figure 5, (1) the trend in $\mathrm{ET}_{o, \mathrm{WR}}$ over 19612010 decreased insignificantly $(j=10)$. The trends in $\mathrm{ET}_{o, \mathrm{WR}}$ over 2015-2099 under both scenarios A2 and B2 decreased insignificantly with both $j=0$. (2) The trend in $P_{\mathrm{WR}}$ during the period of 1961-2010 increased insignificantly $(j=12)$. The trend in $P_{\mathrm{WR}}$ from 2015 to 2099 increased significantly under scenario A2 and insignificantly under scenario B2, both serial structures were time independent $(j=0)$. (3) The trend in $\mathrm{DI}_{\mathrm{WR}}$ from 1961 to 2010 decreased significantly $(j=6)$. The trend in $\mathrm{DI}_{\mathrm{WR}}$ over 2015-2099 under scenario A2 decreased but was insignificant under the influence of series autocorrelation $(j=15)$. The trend in $\mathrm{DI}_{\mathrm{WR}}$ over 1961-2010 under scenario B2 decreased significantly $(j=2)$. (3) Over the period of 1961-2010, $\mathrm{DI}_{\mathrm{WR}}$ decreased significantly, $\mathrm{ET}_{o, \mathrm{WR}}$ decreased insignificantly, and $P_{\mathrm{WR}}$ increased insignificantly. The decreasing trends of $\mathrm{DI}_{\mathrm{WR}}$ indicate less drought stress in the study region.

\section{Discussions}

Uncertainty exists when assessing climate change impacts on hydrologic or meteorological elements. Several studies affirmed that GCMs were the largest uncertainty contributors [54-56]. Li et al. [18] compared the uncertainties from five raw monthly outputs of GCMs under three emission scenarios and concluded that GCMs projected different change trends and magnitudes for rainfall data. Sunyer et al. [30] concluded that the uncertainties were partly due to the variability of the RCM projections and partly due to the variability of the statistical downscaling methods. The results 


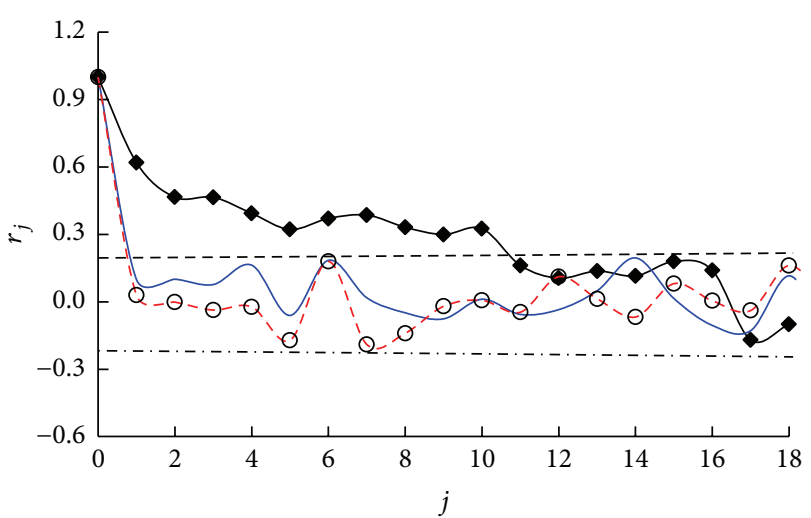

(a) $r_{j}$ of $\mathrm{ET}_{o, \mathrm{WR}}$

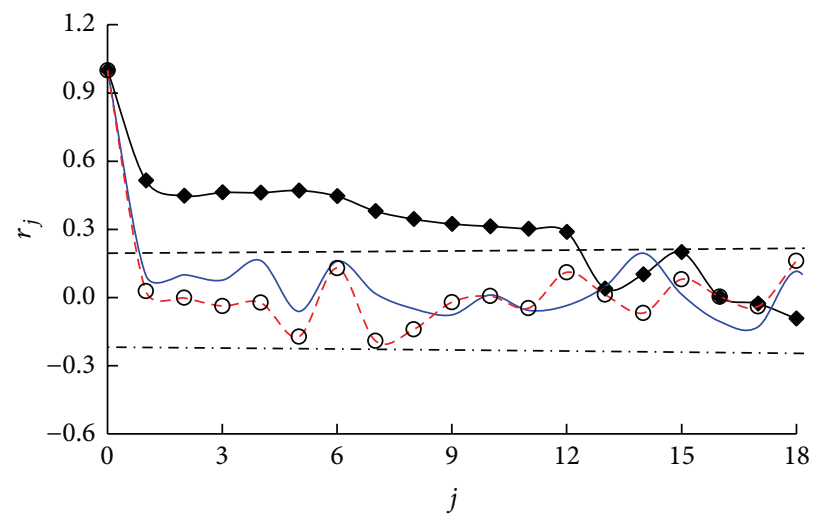

(c) $r_{j}$ of $P_{\mathrm{WR}}$

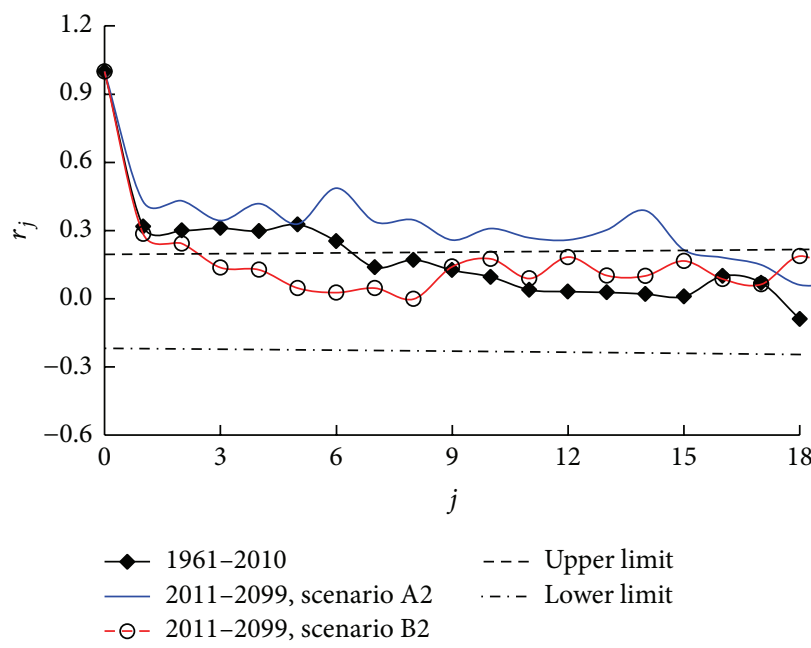

(e) $r_{j}$ of $\mathrm{DI}_{\mathrm{WR}}$

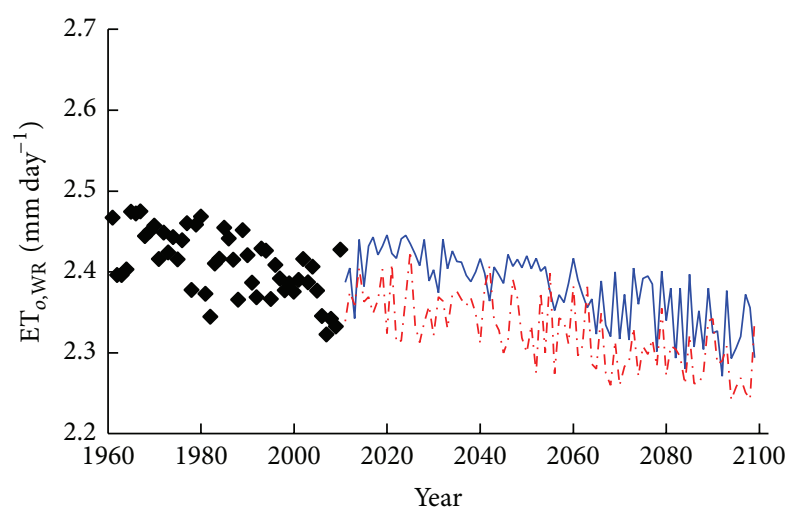

(b) Variations of $\mathrm{ET}_{o, \mathrm{WR}}$

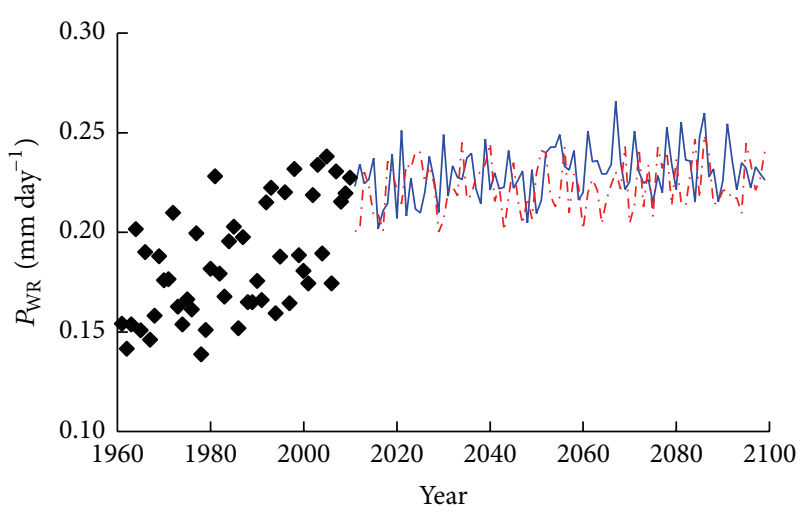

(d) Variations of $P_{\mathrm{WR}}$

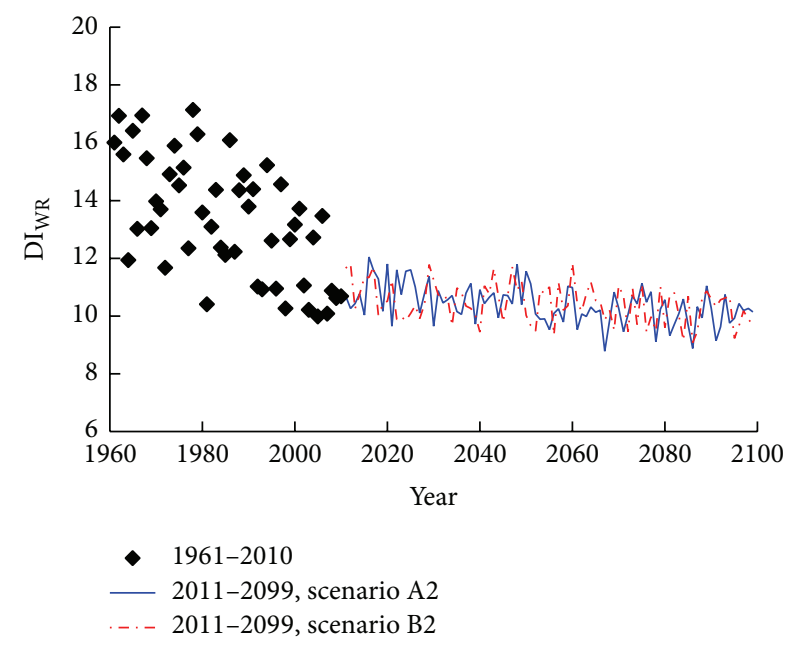

(f) Variations of $\mathrm{DI}_{\mathrm{WR}}$

FIgURE 5: Variations of $\mathrm{ET}_{o, \mathrm{WR}}, P_{\mathrm{WR}}$, and $\mathrm{DI}_{\mathrm{WR}}$ from 1961 to 2099.

from Chen et al. [31] showed that a large uncertainty envelope is associated with the choice of a given empirical downscaling method, as well as the choice of a regional climate model simulation for quantifying the climate change impacts on hydrology. Besides GCMs and downscaling methods, emission scenarios were also a contributor to the model uncertainties, but less important $[18,54]$. For hydrologic applications, the uncertainty due to the hydrological model parameters was also considered minor, and the abrupt changes in lowflow cumulative distribution functions were attributed to uncertainty in statistically downscaled summer rainfall [54].

Only one statistical downscaling method was used in this study. Uncertainty was not assessed but could refer to the other research mentioned above. SDSM 4.2 software is 
convenient for projecting future daily $P$ and $\mathrm{ET}_{o}$ data if historical data is available. Khan et al. [57] concluded that SDSM is the most capable of reproducing various statistical characteristics of observed data in its downscaled results with 95\% confidence level compared to Long Ashton Research Station Weather Generator (LARS-WG) model and artificial neural network model. Frost et al. [38] pointed out that the simple scaling approach provided relatively robust results for a range of statistics when GCM forcing data was used. Although only one downscaling method was used in this study, the results obtained for projected precipitation could be used for future local disaster control and decision making.

The trends for $P_{\mathrm{AM}}, \mathrm{ET}_{o, \mathrm{AM}}$, and $\mathrm{DI}_{\mathrm{AM}}$ series over 19612099 were detected using a more robust method based on the MK test, that is, the MMK test, which considered the autocorrelation effects of the serial structures on trends. From our results, trends changed from significant to insignificant if the lags of serial autocorrelation were high $(j>1)$. The trends of the series tended to be exaggerated using the MK test. This implied that the MK test gave apparent significance of the trends and may mislead the trend detector in understanding of the studied series. The MMK test is strongly recommended for obtaining actual trends of the data series because it removes the exaggerated trends caused by long-duration correlations.

Overall, $P_{\mathrm{WR}}$ showed an increasing trend over 1961-2099. The projected $P_{\mathrm{WR}}$ over 2015-2099 lost its autocorrelation structure, which was unexpected and also indicated that random components in the weather generator may be not enough.

\section{Conclusions}

The statistical downscaling model (SDSM), combined with HadCM3 data and NCEP reanalysis data, was used in this study to project future daily $P$ data under scenarios A2 and B2 for 41 sites in Xinjiang, China. Over the period of 1960-2010, $\mathrm{ET}_{o, \mathrm{AM}}, P_{\mathrm{AM}}$, and $\mathrm{DI}_{\mathrm{AM}}$ ranged from 1.52 to $3.42 \mathrm{~mm}_{\text {day }}{ }^{-1}$, 0.004 to $1.36 \mathrm{~mm} \mathrm{day}^{-1}$, and 1.5 to 479.6 , respectively. Spatial distributions and the trends of $\mathrm{ET}_{o, \mathrm{AM}}, P_{\mathrm{AM}}$, and $\mathrm{DI}_{\mathrm{AM}}$ were investigated considering the autocorrelation structures of the data series. $\mathrm{DI}_{\mathrm{AM}}$ was small in the north and large in the southeast of the study region. $\mathrm{DI}_{\mathrm{AM}}$ varied considerably and generally decreased, indicating a general relief from historical drought.

Ranges of $\mathrm{ET}_{o, \mathrm{AM}}, P_{\mathrm{AM}}$ and $\mathrm{DI}_{\mathrm{AM}}$ over 2015-2099 under scenario A2 were between 1.77 and $2.71 \mathrm{~mm} \mathrm{day}^{-1}, 0.04$ and $0.62 \mathrm{~mm} \mathrm{day}^{-1}$, and 1.9 and 198.5, respectively. Ranges of $\mathrm{ET}_{o, \mathrm{AM}}, P_{\mathrm{AM}}$ and $\mathrm{DI}_{\mathrm{AM}}$ over 2015-2099 under scenario B2 were from 1.65 to $2.72 \mathrm{~mm} \mathrm{day}^{-1}$, from 0.03 to $0.65 \mathrm{~mm}$ day $^{-1}$ and from 1.6 to 130.4 , respectively. The obvious decrease in $\mathrm{DI}_{\mathrm{AM}}$ indicated a continuous relief of drought in the future 8 decades.

The robust trend test combining MK with MKK methods indicated that for the whole region in Xinjiang, trends in $\mathrm{DI}_{\mathrm{WR}}$ decreased significantly both over 1961-2010 and 20152099 under scenario A2 but decreased insignificantly over 2015-2099 under scenario B2. There was an overall relief of drought in Xinjiang both historically and in the coming decades. Robust trend detection method, that is, the MMK test is strongly recommend for autocorrelated data series, in order to detect an "actual" rather than an "apparent" trend and assess the trends objectively.

\section{Conflict of Interests}

The authors declare that there is no conflict of interests regarding the publication of this paper.

\section{Acknowledgments}

The authors acknowledge the Xinjiang Joint Project of China National Science Foundation (U1203182), International Cooperation Key Project in Shannxi, China (2012KW24-01), and Basic Science-Technology Foundation for the Talent Young Scientist in the Universities of China (YQ2013006). Mark Sigouin helped edit the paper. The authors thank the anonymous reviewers, who gave them very constructive and helpful comments.

\section{References}

[1] IPCC, Summary for Policymakers of Climate Change 2007: The Physical Science Basis. Contribution of Working Group I to the Fourth Assessment Report of the Intergovernmental Panel on Climate Change, Cambridge University Press, Cambridge, UK, 2007.

[2] L. Vergni and F. Todisco, "Spatio-temporal variability of precipitation, temperature and agricultural drought indices in Central Italy," Agricultural and Forest Meteorology, vol. 151, no. 3, pp. 301-313, 2011.

[3] A.-E. K. Vrochidou, I. K. Tsanis, M. G. Grillakis, and A. G. Koutroulis, "The impact of climate change on hydrometeorological droughts at a basin scale," Journal of Hydrology, vol. 476, pp. 290-301, 2013.

[4] W. H. Qian, X. L. Shan, and Y. F. Zhu, "Ranking regional drought events in China for 1960-2009," Advances in Atmospheric Sciences, vol. 28, no. 2, pp. 310-321, 2011.

[5] A. K. Mishra and V. P. Singh, "A review of drought concepts," Journal of Hydrology, vol. 391, no. 1-2, pp. 202-216, 2010.

[6] A. K. Mishra and V. P. Singh, "Drought modeling-a review," Journal of Hydrology, vol. 403, no. 1-2, pp. 157-175, 2011.

[7] M. I. Budyko, Climate and Life, Academic Press, Orlando, Fla, USA, 1974.

[8] V. K. Arora, "The use of the aridity index to assess climate change effect on annual runoff," Journal of Hydrology, vol. 265, no. 1-4, pp. 164-177, 2002.

[9] W. C. Palmer, "Meteorologic drought," Weather Bureau Research Paper no. 45, US Department of Commerce, 1965.

[10] W. C. Palmer, "Keeping track of crop moisture conditions, nationwide: the new crop moisture index," Weatherwise, vol. 21, pp. 156-161, 1968.

[11] T. B. McKee, N. J. Doesken, and J. Kleist, "The relationship of drought frequency and duration to time scales," in Proceedings of the 8th Conference on Applied Climatology, American Meteorological Society, Anaheim, Calif, USA, 1993. 
[12] S. E. Hollinger, S. A. Isard, and M. R. Welford, "A new soil moisture dryness index for predicting crop yields," in Proceedings of the 8th Conference on Applied Climatology, pp. 187-190, American Meteorological Society, Anaheim, Calif, USA, 1993.

[13] W. T. Liu and F. N. Kogan, "Monitoring regional drought using the vegetation condition index," International Journal of Remote Sensing, vol. 17, no. 14, pp. 2761-2782, 1996.

[14] S. M. Vicente-Serrano, S. Beguería, and J. I. López-Moreno, "A multiscalar drought index sensitive to global warming: the standardized precipitation evapotranspiration index," Journal of Climate, vol. 23, no. 7, pp. 1696-1718, 2010.

[15] L. Wang, W. Chen, and W. Zhou, "Assessment of future drought in Southwest China based on CMIP5 multimodel projections," Advances in Atmospheric Sciences, vol. 31, no. 5, pp. 1035-1050, 2014.

[16] S. Blenkinsop and H. J. Fowler, "Changes in European drought characteristics projected by the PRUDENCE regional climate models," International Journal of Climatology, vol. 27, no. 12, pp. 1595-1610, 2007.

[17] X. Gao and F. Giorgi, "Increased aridity in the Mediterranean region under greenhouse gas forcing estimated from high resolution simulations with a regional climate model," Global and Planetary Change, vol. 62, no. 3-4, pp. 195-209, 2008.

[18] Z. Li, F. L. Zheng, and W. Z. Liu, "Spatiotemporal characteristics of reference evapotranspiration during 1961-2009 and its projected changes during 2011-2099 on the Loess Plateau of China," Agricultural and Forest Meteorology, vol. 154-155, pp. 147-155, 2012.

[19] P. T. Nastos, N. Politi, and J. Kapsomenakis, "Spatial and temporal variability of the Aridity Index in Greece," Atmospheric Research, vol. 119, pp. 140-152, 2013.

[20] E. J. Burke and S. J. Brown, "Regional drought over the UK and changes in the future," Journal of Hydrology, vol. 394, no. 3-4, pp. 471-485, 2010.

[21] S. L. Grotch and M. C. MacCracken, "The use of general circulation models to predict regional climatic change," Journal of Climate, vol. 4, pp. 286-303, 1991.

[22] H. J. Fowler, S. Blenkinsop, and C. Tebaldi, "Linking climate change modelling to impacts studies: recent advances in downscaling techniques for hydrological modelling," International Journal of Climatology, vol. 27, no. 12, pp. 1547-1578, 2007.

[23] K. F. Ahmed, G. Wang, J. Silander et al., "Statistical downscaling and bias correction of climate model outputs for climate change impact assessment in the U.S. Northeast," Global and Planetary Change, vol. 100, pp. 320-332, 2013.

[24] R. L. Wilby, C. W. Dawson, and E. M. Barrow, "SDSM-a decision support tool for the assessment of regional climate change impacts," Environmental Modelling and Software, vol. 17, no. 2, pp. 147-159, 2002.

[25] R. Mehrotra and A. Sharma, "Development and application of a multisite rainfall stochastic downscaling framework for climate change impact assessment," Water Resources Research, vol. 46, no. 7, Article ID W07526, 2010.

[26] R. Mehrotra, A. Sharma, D. N. Kumar, and T. V. Reshmidevi, "Assessing future rainfall projections using multiple GCMS and a multi-site stochastic downscaling model," Journal of Hydrology, vol. 488, pp. 84-100, 2013.

[27] B. Timbal, "Southwest Australia past and future rainfall trends," Climate Research, vol. 26, no. 3, pp. 233-249, 2004.

[28] B. Timbal, J. M. Arblaster, and S. Power, "Attribution of the late-twentieth-century rainfall decline in southwest Australia," Journal of Climate, vol. 19, no. 10, pp. 2046-2062, 2006.
[29] B. Timbal and D. A. Jones, "Future projections of winter rainfall in southeast Australia using a statistical downscaling technique," Climatic Change, vol. 86, no. 1-2, pp. 165-187, 2008.

[30] M. A. Sunyer, H. Madsen, and P. H. Ang, "A comparison of different regional climate models and statistical downscaling methods for extreme rainfall estimation under climate change," Atmospheric Research, vol. 103, pp. 119-128, 2012.

[31] J. Chen, F. P. Brissette, D. Chaumont, and M. Braun, "Performance and uncertainty evaluation of empirical downscaling methods in quantifying the climate change impacts on hydrology over two North American river basins," Journal of Hydrology, vol. 479, pp. 200-214, 2013.

[32] R. E. Chandler and H. S. Wheater, "Analysis of rainfall variability using generalized linear models: a case study from the west of Ireland," Water Resources Research, vol. 38, no. 10, 2002.

[33] C. Yang, R. E. Chandler, V. S. Isham, and H. S. Wheater, "Spatialtemporal rainfall simulation using generalized linear models," Water Resources Research, vol. 41, Article ID W11415, 2005.

[34] J. P. Hughes, P. Guttorp, and S. P. Charles, "A non-homogeneous hidden Markov model for precipitation occurrence," Journal of the Royal Statistical Society Series C: Applied Statistics, vol. 48, no. 1, pp. 15-30, 1999.

[35] S. D. Tumbo, E. Mpeta, M. Tadross, F. C. Kahimba, B. P. Mbillinyi, and H. F. Mahoo, "Application of self-organizing maps technique in downscaling GCMs climate change projections for Same, Tanzania," Physics and Chemistry of the Earth, vol. 35, no. 13-14, pp. 608-617, 2010.

[36] C. K. Ho, D. B. Stephenson, M. Collins, C. A. T. Ferro, and S. J. Brown, "Calibration strategies: a source of additional uncertainty in climate change projections," Bulletin of the American Meteorological Society, vol. 93, no. 1, pp. 21-26, 2012.

[37] S.-T. Chen, P.-S. Yu, and Y.-H. Tang, "Statistical downscaling of daily precipitation using support vector machines and multivariate analysis," Journal of Hydrology, vol. 385, no. 1-4, pp. 1322, 2010.

[38] A. J. Frost, S. P. Charles, B. Timbal et al., "A comparison of multisite daily rainfall downscaling techniques under Australian conditions," Journal of Hydrology, vol. 408, no. 1-2, pp. 1-18, 2011.

[39] M. D. Zhou, Drought index and crop water requirement prediction under climate change scenarios in Xinjiang Region [M.S. thesis], Northwest Agriculture and Forestry University, Yangling, China, 2014, (Chinese).

[40] Y. Shi, Y. Shen, E. Kang et al., "Recent and future climate change in northwest China," Climatic Change, vol. 80, no. 3-4, pp. 379393, 2007.

[41] B. Wang, M. Zhang, J. Wei et al., "Changes in extreme events of temperature and precipitation over Xinjiang, northwest China, during 1960-2009," Quaternary International, vol. 298, pp. 141151, 2013.

[42] Y. Chen, H. Deng, B. Li, Z. Li, and C. Xu, "Abrupt change of temperature and precipitation extremes in the arid region of Northwest China," Quaternary International, vol. 336, pp. 3543, 2014.

[43] Q. You, K. Fraedrich, J. Min et al., "Can temperature extremes in China be calculated from reanalysis?" Global and Planetary Change, vol. 111, pp. 268-279, 2013.

[44] C. Gordon, C. Cooper, C. A. Senior et al., "The simulation of SST, sea ice extents and ocean heat transports in a version of the Hadley Centre coupled model without flux adjustments," Climate Dynamics, vol. 16, no. 2-3, pp. 147-168, 2000. 
[45] Y. Cao and G. H. Zhang, "Applicability evaluation of global circulation models in the Yellow River Basin," Journal of China Hydrology, vol. 29, no. 5, pp. 1-5, 22, 2009.

[46] R. G. Allen, L. S. Periera, D. Raes, and M. Smith, "Crop evapotranspiration: guidelines for computing crop requirements," Irrigation and Drainage Paper No. 56, FAO, Rome, Italy, 1998.

[47] H. B. Mann, "Nonparametric tests against trend," Econometrica. Journal of the Econometric Society, vol. 13, pp. 245-259, 1945.

[48] M. G. Kendall, Rank Auto-Correlation Methods, Charles Griffin, London, UK, 1975.

[49] M. Cannarozzo, L. V. Noto, and F. Viola, "Spatial distribution of rainfall trends in Sicily (1921-2000)," Physics and Chemistry of the Earth, vol. 31, no. 18, pp. 1201-1211, 2006.

[50] F. Topaloğlu, "Regional trend detection of Turkish river flows," Nordic Hydrology, vol. 37, no. 2, pp. 165-182, 2006.

[51] S. Yue and C. Y. Wang, "Regional streamflow trend detection with consideration of both temporal and spatial correlation," International Journal of Climatology, vol. 22, no. 8, pp. 933-946, 2002.

[52] Y. Li, R. Horton, T. Ren, and C. Chen, "Prediction of annual reference evapotranspiration using climatic data," Agricultural Water Management, vol. 97, no. 2, pp. 300-308, 2010.

[53] P. K. Sen, "Estimates of the regression coefficient based on Kendall's tau," Journal of the American Statistical Association, vol. 63, pp. 1379-1389, 1968.

[54] R. L. Wilby and I. Harris, "A framework for assessing uncertainties in climate change impacts: low-flow scenarios for the River Thames, UK," Water Resources Research, vol. 42, no. 2, Article ID W02419, 2006.

[55] M. Deque, D. P. Rowell, D. Lüthi et al., "An intercomparison of regional climate simulations for Europe: assessing uncertainties in model projections," Climatic Change, vol. 81, no. 1, pp. 53-70, 2007.

[56] J. Chen, F. P. Brissette, A. Poulin, and R. Leconte, "Overall uncertainty study of the hydrological impacts of climate change for a Canadian watershed," Water Resources Research, vol. 47, no. 12, Article ID W12509, 2011.

[57] M. S. Khan, P. Coulibaly, and Y. Dibike, "Uncertainty analysis of statistical downscaling methods," Journal of Hydrology, vol. 319, no. 1-4, pp. 357-382, 2006. 

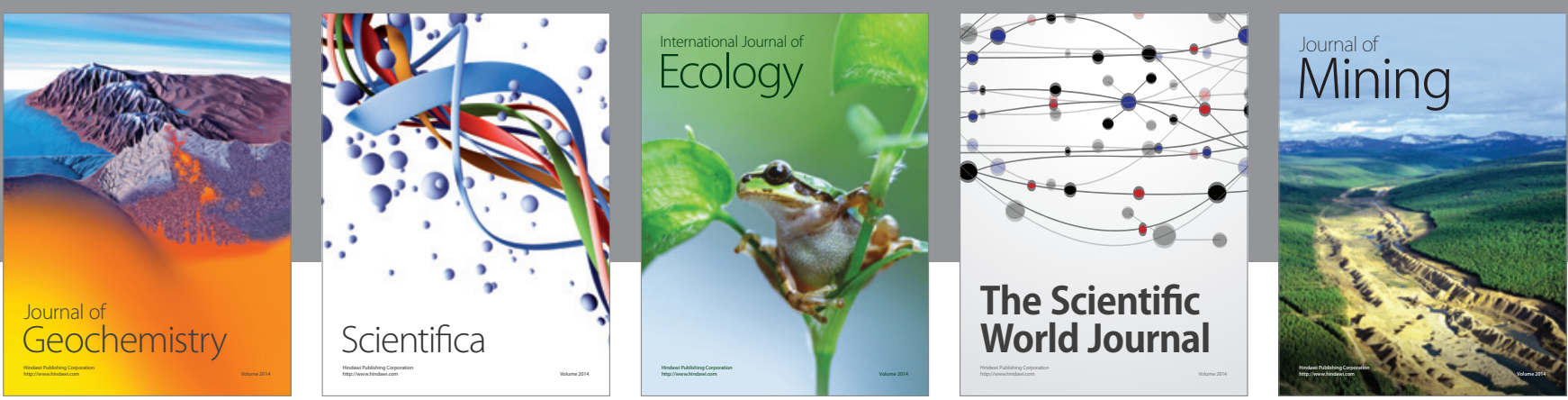

The Scientific World Journal
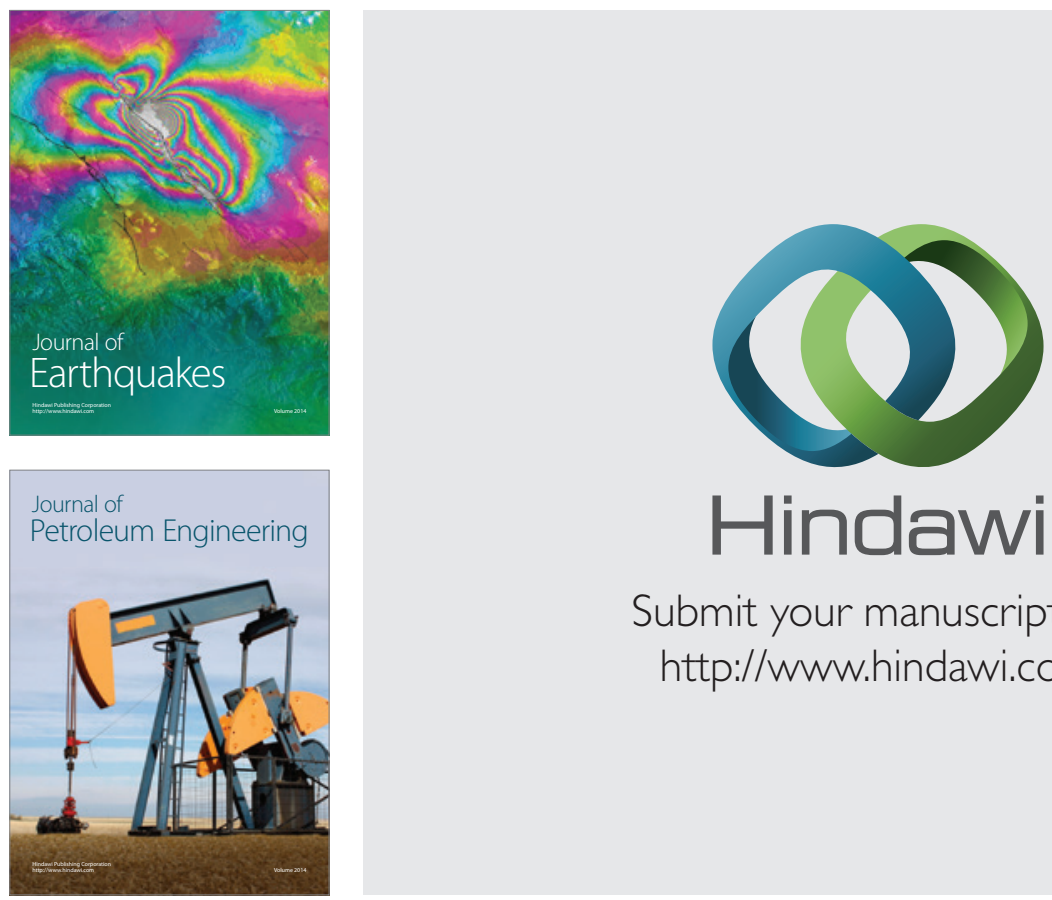

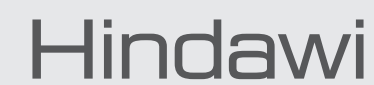

Submit your manuscripts at

http://www.hindawi.com
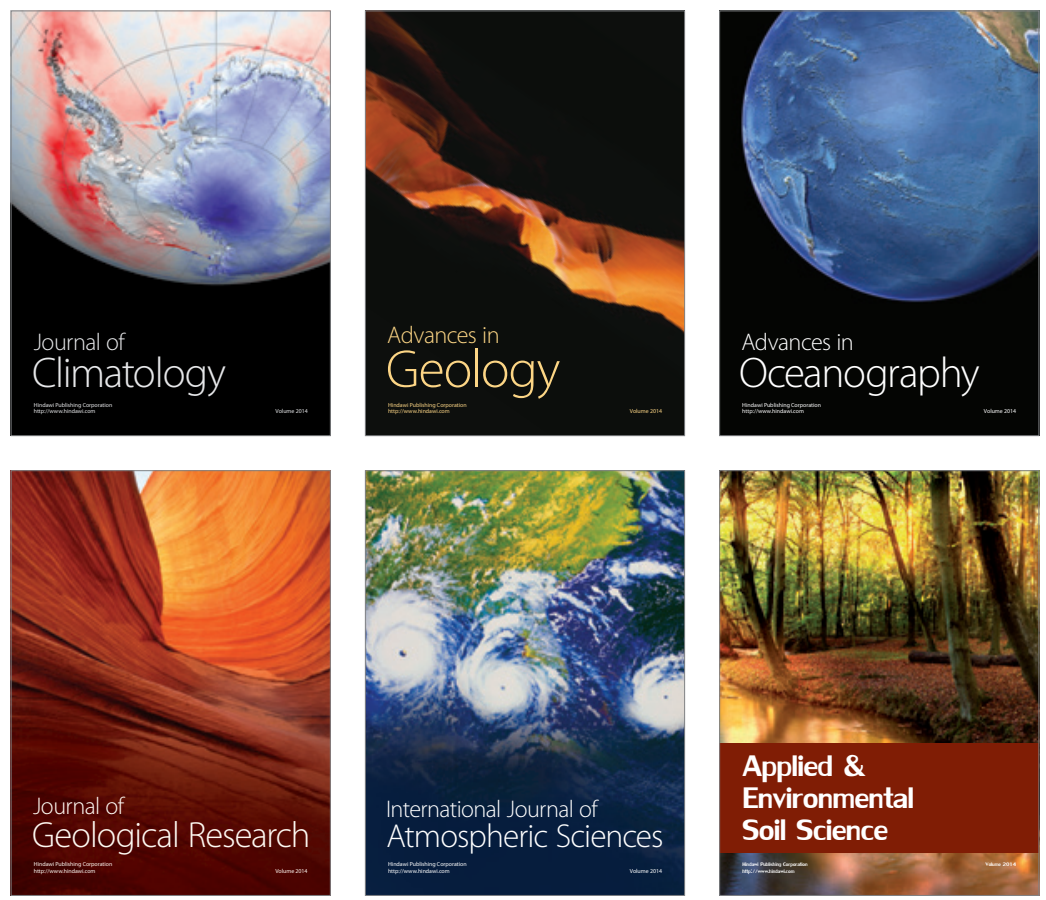
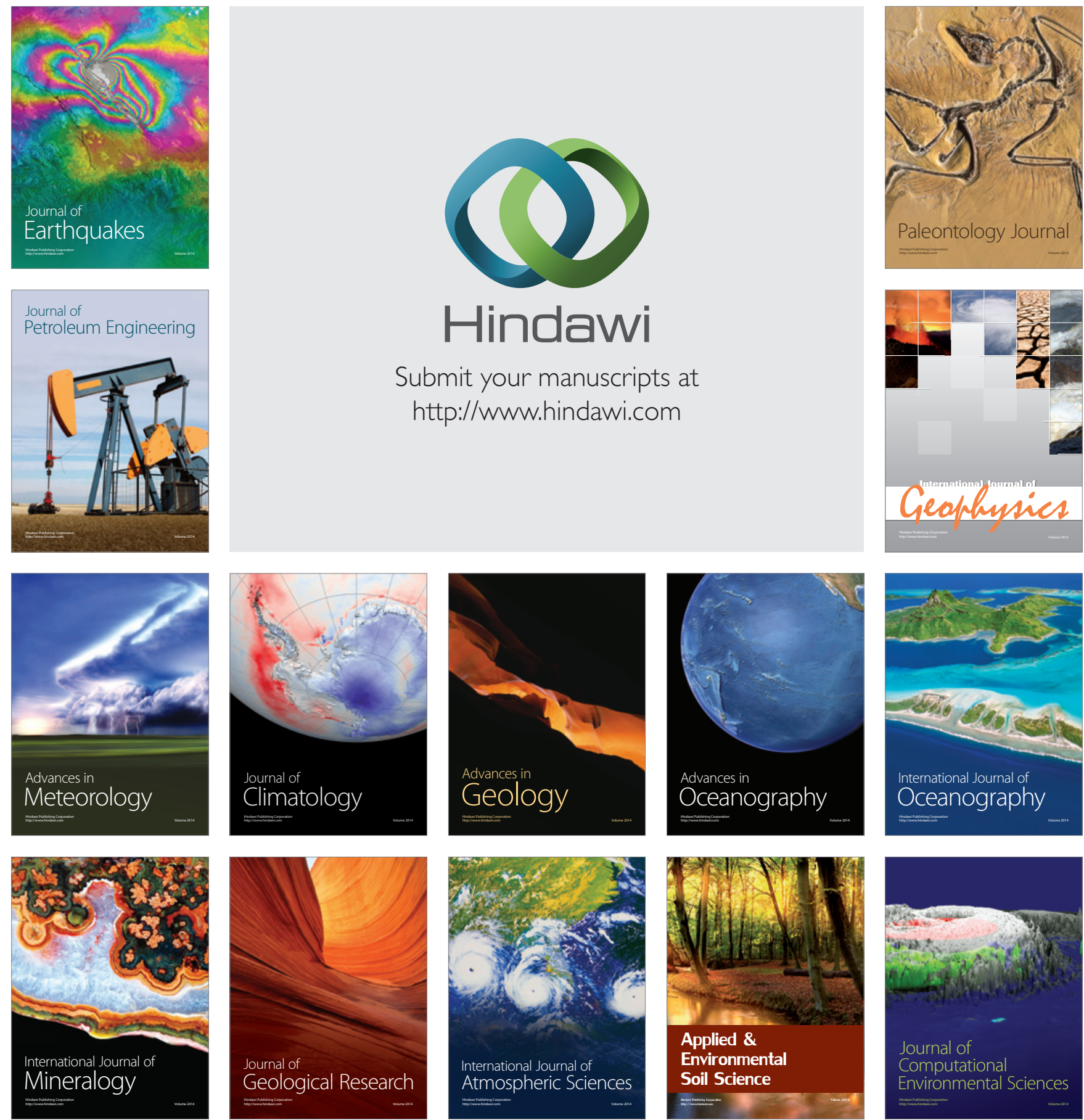